UnB - UNIVERSIDADE DE BRASÍLIA

FGA - FACULDADE GAMA

PROGRAMA DE PÓS-GRADUAÇÃO EM ENGENHARIA BIOMÉDICA

\title{
REVISÃO SISTEMÁTICA DA USABILIDADE EM DISPOSITIVOS MÉDICOS
}

MARYLENE SOUSA GUIMARÃES ROMA

ORIENTADOR: DR. EULER DE VILHENA GARCIA

DISSERTAÇÃO DE MESTRADO EM ENGENHARIA BIOMÉDICA

PUBLICAÇÃO: 052A/2016

BRASÍLIA/DF: JULHO/2016 


\title{
UNIVERSIDADE DE BRASÍLIA \\ FACULDADE UNB GAMA \\ ENGENHARIA BIOMÉDICA
}

\section{REVISÃO SISTEMÁTICA DA USABILIDADE EM DISPOSITIVOS MÉDICOS}

\author{
MARYLENE SOUSA GUIMARÃES ROMA
}

DISSERTAÇÃO DE MESTRADO SUBMETIDA À FACULDADE UNB GAMA DA UNIVERSIDADE DE BRASÍLIA, COMO PARTE DOS REQUISITOS NECESSÁRIOS PARA A OBTENÇÃO DO TÍTULO DE MESTRE EM ENGENHARIA BIOMÉDICA.

APROVADA POR:

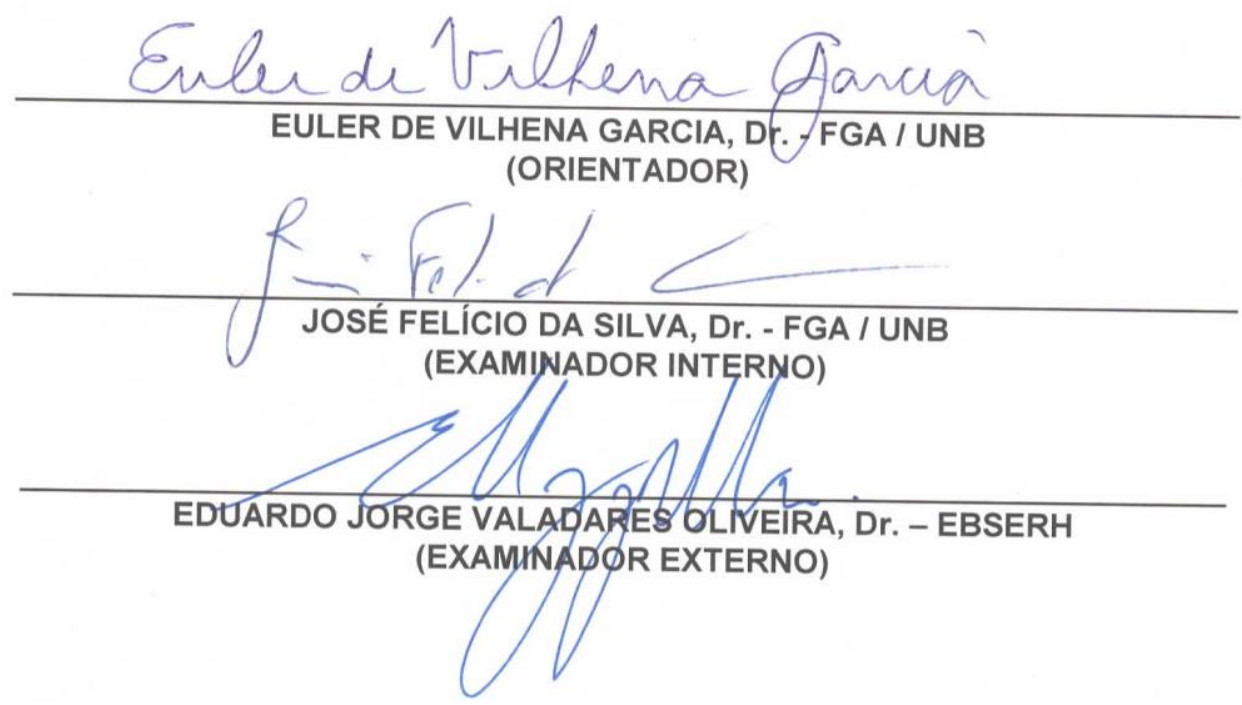


BRASÍLIA/DF, 01 DE JULHO DE 2016.

\section{FICHA CATALOGRÁFICA}

\section{MARYLENE SOUSA GUIMARÃES ROMA}

REVISÃO SISTEMÁTICA DA USABILIDADE EM DISPOSITIVOS MÉDICOS, Distrito Federal 2016.

No.p.79, 210 x 297 mm (FGA/UnB Gama, Mestre, Engenharia Biomédica, 2016). Dissertação de Mestrado - Universidade de Brasília. Faculdade Gama. Programa de PósGraduação em Engenharia Biomédica.

1. USABILIDADE 2. ENGENHARIA DA USABILIDADE

3. REVISÃO SISTEMÁTICA

I. FGA UnB Gama/ UnB. II. Revisão Sistemática da Usabilidade em Dispositivos Médicos (série)

\section{REFERÊNCIA BIBLIOGRÁFICA}

ROMA, M. S. G. (2016). REVISÃO SISTEMÁTICA DA USABILIDADE EM DISPOSITIVOS MÉDICOS. Dissertação de Mestrado em Engenharia Biomédica, Publicação No. 052A/2016, Programa de Pós-Graduação em Engenharia Biomédica, Faculdade Gama, Universidade de Brasília, Brasília, DF, no.p.79

\section{CESSÃO DE DIREITOS}

AUTOR: MARYLENE SOUSA GUIMARÃES ROMA.

TÍTULO: REVISÃO SISTEMÁTICA DA USABILIDADE EM DISPOSITIVOS MÉDICOS

GRAU: Mestre

ANO: 2016

É concedida à Universidade de Brasília permissão para reproduzir cópias desta dissertação de mestrado e para emprestar ou vender tais cópias somente para propósitos acadêmicos e científicos. O autor reserva outros direitos de publicação e nenhuma parte desta dissertação de mestrado pode ser reproduzida sem a autorização por escrito do autor.

ANO 2016

ENDEREÇO. SHIGS 711 BLOCO U CASA 38 - ASA SUL

CEP 70361-721 Brasília, DF - Brasil. 


\section{DEDICATÓRIA}

Para todos que longe ou perto me transferem os mais nobres ensinamentos e que fazem parte da minha história: meus pais, meus irmãos, minha família, amigos e mestres. 


\section{AGRADECIMENTOS}

Agradeço a Deus, que me deu sabedoria e perseverança em toda a minha jornada.

Minha mais profunda gratidão, aos meus pais, Edmilson Leite Guimarães, de quem herdei o raciocínio lógico, e Maria Madalena de Souza, que me deu a possibilidade de adquirir conhecimentos e experiências tão importantes, e que foram a todo momento aproveitados.

Aos meus irmãos, Edson James e Edmilson Filho (Cel.Leite), que me ensinaram nas brincadeiras de menino, a sobreviver e ser forte, mesmo delicada.

Aos meus avós (in memoriam), Maria Mattos (matriarca da família) e José Bogéa, pelo exemplo de firmeza.

Ao meu marido Valter Roma Junior, e meus filhos Renato e Felipe Roma, que compreenderam e me incentivaram a todo momento, mesmo nas minhas ausências.

À minha eterna inspiração Profa. Laura Cariello (in memoriam), por me ensinar que a docência é uma arte e uma paixão, que ela tanto soube exercitar.

Ao Prof. Tarcísio Araujo Kuhn Ribeiro, Diretor-Geral do Campus Ceilândia, por me propiciar e permitir participar deste programa de Mestrado.

À equipe do Núcleo de Engenharia (NENG) que esteve sempre ao meu lado torcendo!

Ào Prof. Dr. José Felício da Silva, por ser minha inspiração na paixão pela Engenharia Biomédica, pela valiosa contribuição na minha decisão sobre os primeiros passos para a pesquisa, me indicando para ler o livro do Webster, Medical Instrumentation.

Minha imensa gratidão, ao meu nobre orientador, Prof. Dr. Euler de Vilhena Garcia, pelas cordiais discussões, inestimáveis aconselhamentos, orientações e ensinamentos, pela valiosa contribuição na construção desta Dissertação.

Ao corpo docente do Programa de Pós-graduação em Engenharia Biomédica da Faculdade UnB Gama, Universidade de Brasília, em especial ao Prof. Dr. José Felício da Silva, Prof. Dr. Euler de Vilhena Garcia, Prof. Dr. Gerardo Antônio, Profa. Dra. Marília Miranda Forte, Prof. Dr. Marcelino, Prof. Dr. Sérgio Ricardo Menezes Mateus, Profa. Dra. Vera Regina da Silva Marães, por fazerem parte da minha valiosa formação.

Agradeço às competentes secretárias do Programa de Pós-graduação, Ana Paula, Cássia e sua equipe, pelo apoio e solicitude durante todo este percurso.

À coordenadora do Programa de Pós-graduação, Profa. Dra. Lourdes Mattos Brasil, pelo incentivo aos novos e sonhadores pesquisadores, e ao coordenador desta gestão Prof. Dr. Cristiano Jacques Miosso Rodrigues Mendes, pelo apoio incondicional. 


\title{
RESUMO
}

\section{REVISÃO SISTEMÁTICA DA USABILIDADE EM DISPOSITIVOS MÉDICOS}

\author{
Autor: MARYLENE SOUSA GUIMARÃES ROMA \\ Orientador: Prof. Dr. Euler de Vilhena Garcia \\ Programa de Pós-Graduação em Engenharia Biomédica \\ Brasília, Julho de 2016.
}

Introdução: O sistema de cuidados com a saúde depende da tecnologia médica, que vem crescendo com a sua complexidade funcional e a preocupação com o projeto e desenvolvimento de novos dispositivos médicos (DM). A incidência de eventos adversos em pacientes faz com que o Brasil se destaque negativamente, onde parte desses eventos poderiam ser prevenidos, e ainda possui relação direta com erros de utilização, onde poderiam ser minimizados com a participação do usuário no projeto (user-centered design) do DM. Neste aspecto em particular, o Brasil ainda não se apercebeu da relação entre eventos adversos e o processo de fabricação de DM. Objetivo: Este trabalho realizou uma revisão sistemática de publicações em Usabilidade de DM. Resultados: Após a aplicação dos critérios de inclusão e exclusão, finalizamos com 145 (cento e quarenta e cinco) publicações, para responder à seis questões, obtivemos na: Questão 1: Onde está sendo a APLICAÇÃO dos estudos em Engenharia de Usabilidade? Obtendo 49\% (71 de 144) dos artigos que aplicaram os estudos de Usabilidade em Apenas Hardware, e 14,5\% (21 de 144) para Apenas Software, 6,9\% (10 de 144) nos Processos e 2,1\% (3 de 144) avaliaram Software e Processos, e para Hardware e Software concomitantemente 11 de 144 (7,6\%); Hardware e Processos, 6 de 144 (4,1\%), e Hardware, Software e Processos 0,7\% (1 de 144). Questão 2: Quais os OBJETIVOS DOS ESTUDOS mais utilizados pelos pesquisadores? 22,4\% (44 de 196) dos artigos aplicaram ainda no período de Desenvolvimento do Produto (Formativo), contra 32,1\% (63 de 196) executadas após fabricação na Avaliação do Produto (Somativo). Para Testes Clínicos Experimentais cerca 28,6\% (56 de 196). Dos artigos que aproveitaram da análise do Gerenciamento de Risco, 6,6\% (13 de 196), e no Gerenciamento de Falhas 12 de 196 (6,1\%), e os que utilizaram Educação, Capacitação ou Treinamento 4,1\% (8 de 196). Questão 3: Quais a PRINCIPAIS TÉCNICAS de Usabilidade empregadas? Para a Análise de Tarefas 31,6\% (62 de 196), e para a Simulação de Cenários/ Ambientes Clínicos Simulados, 18,5\% (36 de 196). Para os que aplicaram Questionários nas avaliações 12,8\% (25 de 196), e para as Entrevistas 8,2\% (16 de 196). Utilizaram-se da Engenharia de Fatores Humanos 7,7\% (15 de 196). E a técnica Grupos Focais e Análise Cognitiva igualmente 11 de 196 (5,6\%). E em Outros, 10 de 196 (5,1\%). Para as Heurísticas e Interação HomemMáquina, igualmente 5 de 196 (2,6\%), Questão 4: Qual o PÚBLICO-ALVO? Em 64,9 \% (96 de 148) aplicaram seus estudos atendendo os Pacientes/Usuários Leigos, de forma geral, e dentre estes 60,8\% (90 de 96) exclusivamente os Pacientes/Usuários Leigos (sem restrição) e 4,1\% (6 de 96) para Deficientes/Idosos. Aplicaram Usabilidade para Médicos/Residentes 13,5\% (20 de 148), para Técnicos/Auxiliares/Estudantes, 8,8\% (13 de 148), aos Enfermeiros 
7,4\% (11 de 148). E os Não Especificados 8 de 148 (5,4\%). Questão 5: Quais as ESPECIALIDADES encontradas? Das especialidades, destaca-se a Gastroenterologia com 9 de 54 (16,7\%), as Imagens/Medicina Nuclear 7 de 54 (13\%), para a Anestesiologia 7,4\% (4 de 54), na Fisioterapia/Reabilitação 4 de 54 (7,4\%), na área Respiratória/Pulmonar 7,4\% (4 de 54). No Diagnóstico, na Endocrinologia e na Neurologia foram igualmente 5,6\% (3 de 54). Para a Urologia 5,6\% (3 de 54), na Cardiologia 3,7\% (2 de 54), em Nefrologia 2 de 54 $(3,7 \%)$, na Oftalmologia, Oncologia e Ortopedia/Geriatria/Reumatologia igualmente 3,7\% (2 de 54). E a Dermatologia, Hematologia, Odontologia e Veterinária, receberam igualmente 1,9\% (1 de 54). E finalizando a Questão 6: Quais os LOCAIS DE APLICAÇÃO? No local EAS (Estabelecimentos de Assistência a Saúde), foram 48\% (36 de 75). Para os estudos em Homecare 25\% (19 de 75). No local Cirurgia/Cuidados Intensivos, o número foi de $8 \%$ (6 de 75). Na Emergência/Pronto Socorro, $7 \%$ (5 de 75), e para a Telemedicina, 5\% (4 de 75). Para o Laboratório de Análises Clínicas foram 4\% (3 de 75) e no Ambulatório e o Laboratório de Eletrônica/Automação foram igualmente 1\% (1 de 75) dos artigos revisados.

Palavras-chave: Usabilidade, Engenharia da Usabilidade, Revisão Sistemática. 


\title{
SYSTEMATIC USABILITY MEDICAL DEVICES REVIEW
}

\author{
Author: MARYLENE SOUSA GUIMARÃES ROMA \\ Supervisor: Dr. Euler de Vilhena Garcia \\ Post-Graduation Program in Biomedical Engineering \\ Brasília, July of 2016.
}

Introduction: The system of health care depends on medical technology, which has been growing with its functional complexity and concern with the design and development of new medical devices $(M D)$. The incidence of adverse events in patients makes Brazil to stand out negatively, since part of these events could have been prevented. Also, some of them are direct related to misuse, that could have been minimized with the user's participation in the project (user-centered design) of the MD. In this particular aspect, Brazil still has not realized the relationship between adverse events and the MD manufacturing process. Objective: This study performed a systematic review of publications in Usability of MD. Results: After using the inclusion and exclusion criteria, we ended up with 145 (one hundred forty-five) publications to answer to six questions. We got the following results. Question 1: Where is it happening the APPLICATION of studies in Usability Engineering? We got 49\% (71 out of 144) of the articles that applied studies of Usability in "Only Hardware", and 14.5\% (21 out of 144) for "Only Software", 6.9\% (10 out of 144) in "Processes" and 2.1\% (3 out of 144) evaluated "Software and Processes". For "Hardware and Software" concomitantly 11 out of 144 (7.6\%); for "Hardware and Processes", 6 out of 144 (4.1\%), and for "Hardware, Software and Processes", $0.7 \%$ (1 144). Question 2: What are the STUDY OBJECTIVES most used by researchers? 22.4\% (44 out of 196) of the articles applied them in the process of "Product Development (Formative)", against 32.1\% (63 out of 196) that used them after manufacturing, in the "Product Evaluation (Summative)." To "Clinical Trials Experiments" it was about 28.6\% (56 out of 196). Among the articles that took advantage of the analysis of "Risk Management", it was 6.6\% (13 out of 196), and among the ones that used the "Fault Management", we found 12 out of 196 (6.1\%), and for those that used "Education, Management or Training", we found 4.1\% (8 out of 196). Question 3: What are the MAIN TECHNIQUES of usability applied? For the "Task Analysis", the result was of 31.6\% (62 out of 196), and for the "Scenario simulation/Simulated Clinical Environments", 18.5\% (36 out of 196). For those that used "Questionnaires" in their evaluations, the result was of 12.8\% (25 of 196), and for the ones that used "Interviews", 8.2\% (16 out of 196). The results of the ones the used "Human Factors Engineering" were 7.7\% (15 out of 196). The techniques "Focus Groups" and "Cognitive Analysis" appeared in 11 of 196 (5.6\%). For other options, we found 10 out of 196 (5.1\%). For "Heuristics and Interaction Human-Machine, both represented 5 out of 196 (2.6\%) Question 4: What is the TARGET audience? In 64.9\% (96 out of 148), they applied their studies considering the "Patients/ Lay Users," in general, and among these 60.8\% (90 
of 96) only "Patients/ Lay Users (with no restriction)". Also, 4.1\% (6 out of 96) for "Disabled/Elderly. It was used Usability for "Doctors/Residents" by 13.5\% (20 of 148) for "Technicians/Auxiliar/ Students", 8.8\% (13 out of 148), for the "Nurses" 7.4\% (11 out of 148). And the "Unspecified", 8 out of 148 (5.4\%). Question 5: What were the SPECIALTIES found? Among the specialties analyzed, "Gastroenterology" is highlighted with 9 out of 54 (16.7\%), in "Images/Nuclear Medicine", 7 out of 54 (13\%), in "Anesthesiology" 7.4\% (4 of 54), in "Physiotherapy /Rehabilitation" 4 out of 54 (7.4\%), in "Respiratory/Pulmonary" 7.4\% (4 out of 54). In "Diagnostics", "Endocrinology" and "Neurology" it was equally 5.6\% (3 out of 54). For "Urology" 5.6\% (3 out of 54), in "Cardiology" 3.7\% (2 out of 54), in "Nephrology" 2 out of 54 (3.7\%), in "Ophthalmology", "Oncology" and" Orthopedics/Geriatrics/ Rheumatology" equally 3.7\% (2 out of 54). And "Dermatology, Hematology, Dentistry and Veterinary", equally received 1.9\% (1 out of 54). Finally, question 6: What are the LOCATIONS OF APPLICATION? In the EAS (Health Care Institutions), the result was 48\% (36 out of 75). For studies in Homecare, it was 25\% (19 out of 75). Considering "Surgery/Intensive Care", the figure was 8\% (6 out of 75). In "Emergency", 7\% (5 out of 75), and for the "Telemedicine", 5\% (4 out of 75). For "Clinical Analysis Laboratory" the results were of 4\% (3 out of 75) and for "Clinic" and "Laboratory of Electronics/Automation", were equally 1\% (1 out of 75) of the articles analyzed.

Keywords: Usability, Usability Engineering, Systematic Review. 


\section{SUMÁRIO}

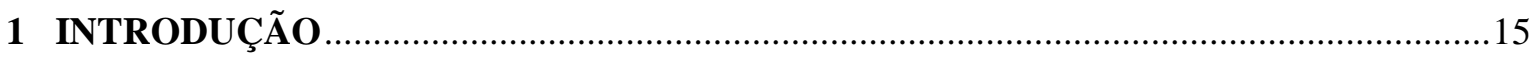

1.1. CONTEXTUALIZAÇÃO E FORMULAÇÃO DO PROBLEMA ………….......................15

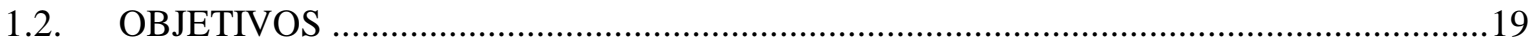

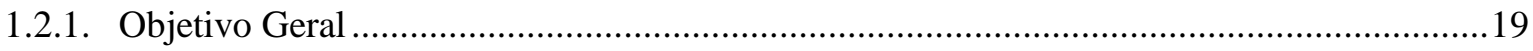

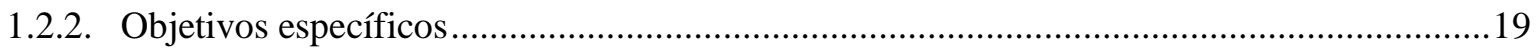

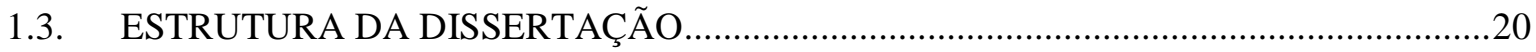

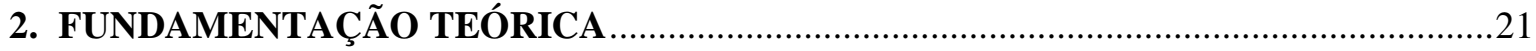

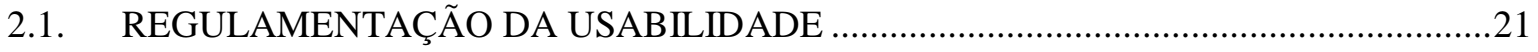

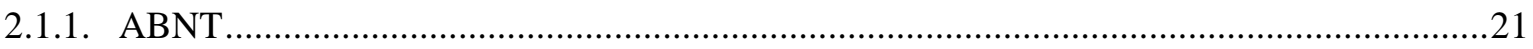

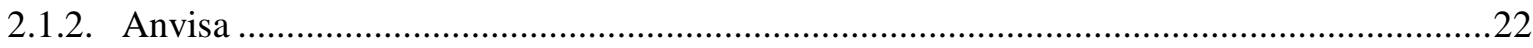

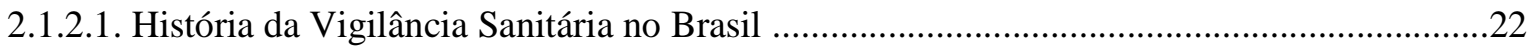

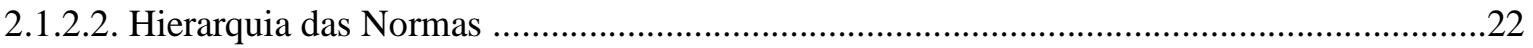

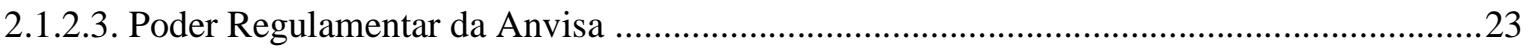

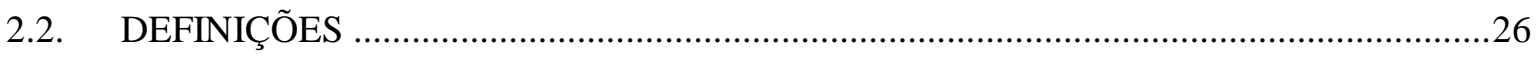

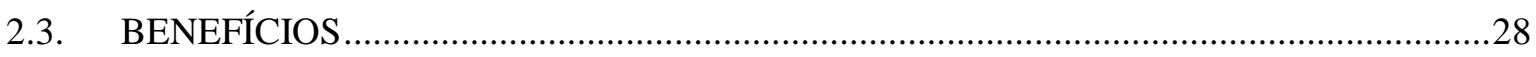

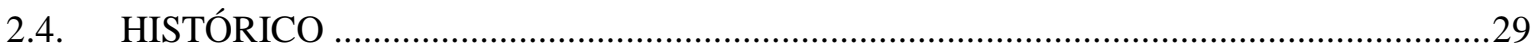

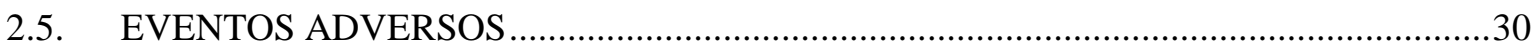

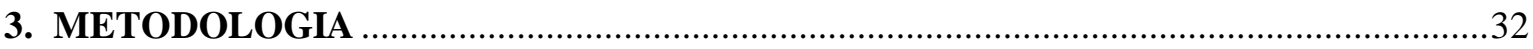

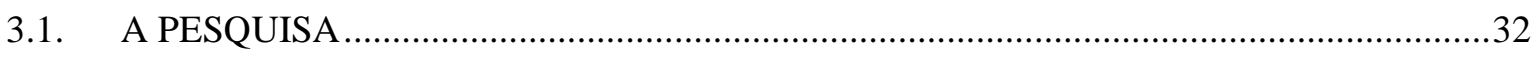

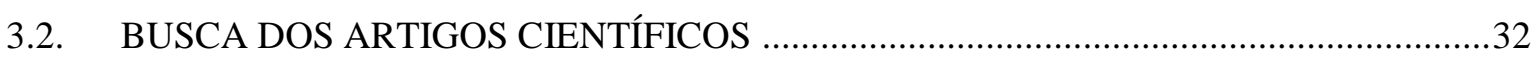

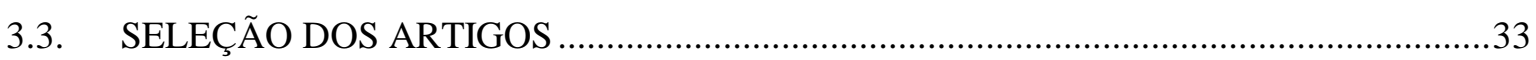

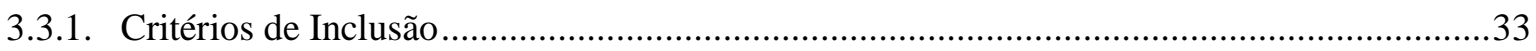

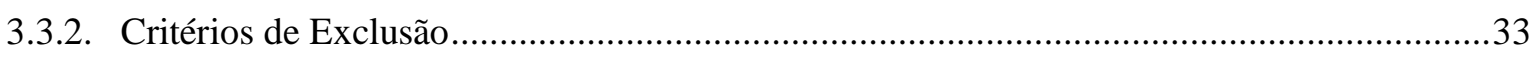

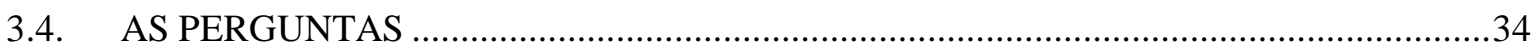

3.4.1. QUESTÃO 1: Onde está sendo a APLICAÇÃO dos estudos em Engenharia De Usabilidade 34

3.4.2. QUESTÃO 2: Quais os OBJETIVOS DOS ESTUDOS em Engenharia de Usabilidade mais utilizados pelos pesquisadores?

3.4.3. QUESTÃO 3: Quais as principais TÉCNICAS DE USABILIDADE empregadas nos estudos?

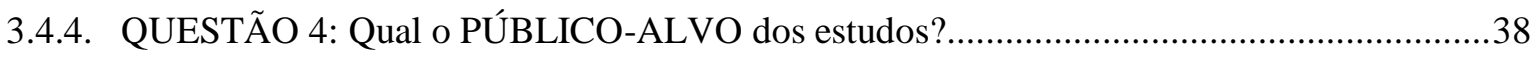

3.4.5. QUESTÃO 5: Quais as ESPECIALIDADES encontradas nos estudos? ...............................38

3.4.6. QUESTÃO 6: Quais os LOCAIS DE APLICAÇÃO dos estudos?........................................39 


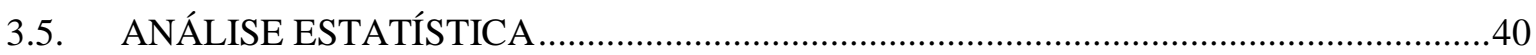

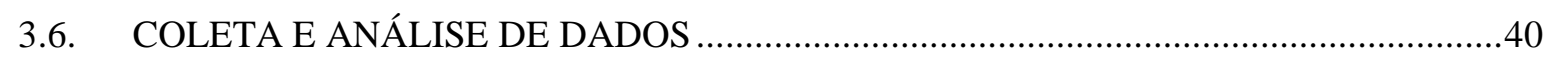

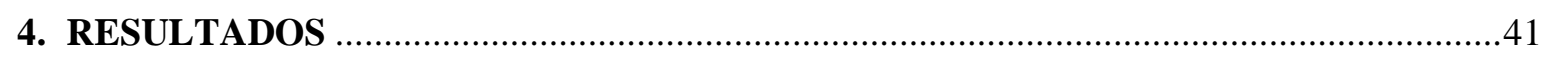

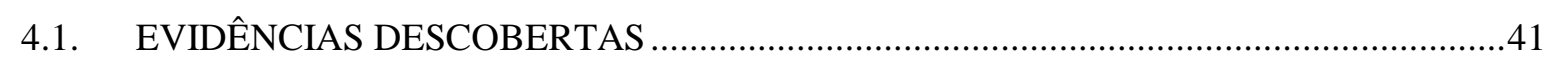

4.1.1. Questão 1: Onde está sendo a APLICAÇÃO dos estudos em engenharia de usabilidade? ..41

4.1.2. Questão 2: Quais os OBJETIVOS dos estudos em engenharia de usabilidade mais utilizados pelos pesquisadores?

4.1.3. Questão 3: Quais a PRINCIPAIS TÉCNICAS de usabilidade que mais estão sendo

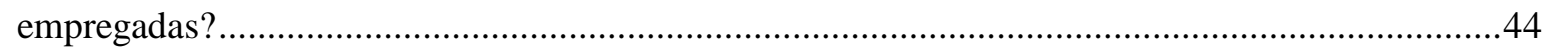

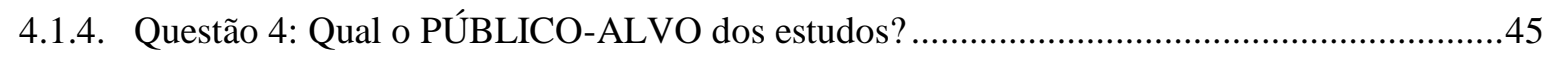

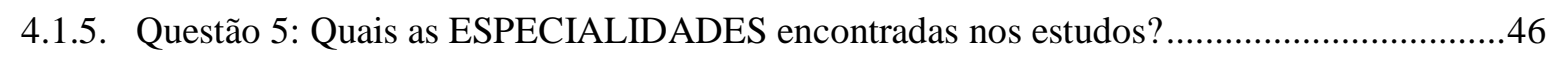

4.1.6. Questão 6: Quais os LOCAIS DE APLICAÇÃO dos estudos? ............................................47

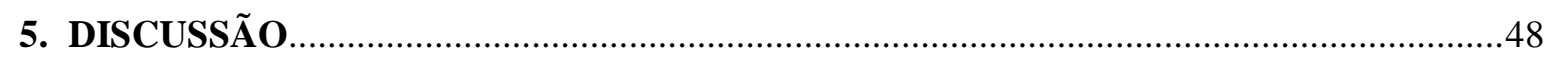

5.1. QUESTÃO 1: Quais as APLICAÇÕES dos estudos? ......................................................48

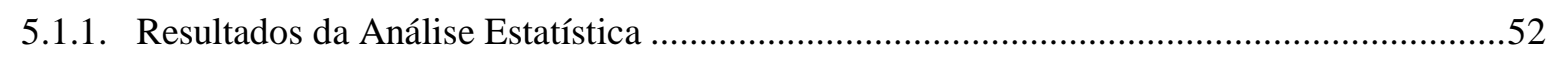

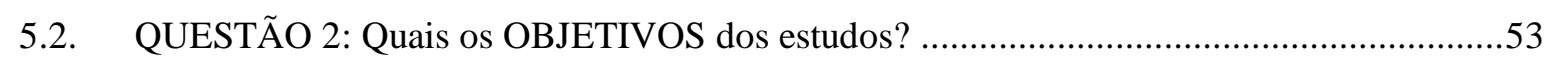

5.3. QUESTÃO 3: Quais as PRINCIPAIS TÉCNICAS empregadas?.........................................56

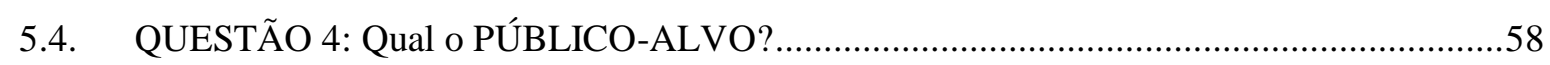

5.5. QUESTÃO 5: Quais as ESPECIALIDADES encontradas? ................................................58

5.6. QUESTÃO 6: Quais os LOCAIS DE APLICAÇÃO dos estudos?......................................60

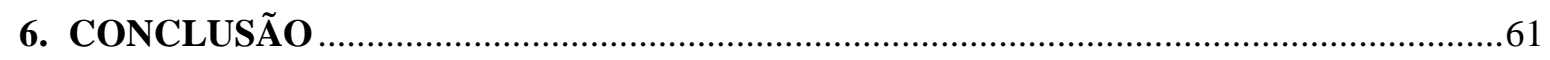

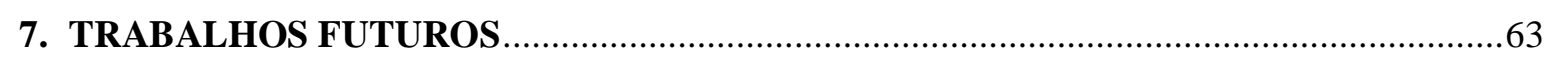

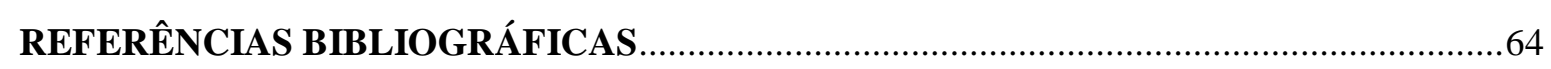




\section{LISTA DE TABELAS}

Tabela 1: Resultados da triagem: APLICAÇÃO de Usabilidade ....................................................... 28

Tabela 2: Resultados da triagem: OBJETIVOS dos estudos de Usabilidade ................................... 29

Tabela 3: Resultados da triagem: PRINCIPAIS TÉCNICAS de Usabilidade empregadas .............. 30

Tabela 4: Resultados da triagem: PÚBLICO ALVO dos estudos de Usabilidade ............................ 31

Tabela 5: Resultados da triagem: ESPECIALIDADES encontradas nos estudos ............................ 32

Tabela 6: Resultados da triagem: LOCAIS DE APLICAÇÃO dos estudos de Usabilidade ............ 33 


\section{LISTA DE FIGURAS}

Figura 1: Fluxograma dos resultados do processo de triagem para a revisão sistemática

Figura 2: Resultados estatísticos da antiguidade dos artigos sobre Hardware, Software e Processos, de 122 Artigos - Últimos 10 anos: ANOVA, $\mathrm{p}=0$ 0,220; Chi-quadrado: $\mathrm{p}<0,001$ 


\section{LISTA DE SÍMBOLOS, NOMENCLATURAS E ABREVIAÇÕES}

ABNT - Associação Brasileira de Normas Técnicas

ANSI - American National Standards Institute

Anvisa - Agência Nacional de Vigilância Sanitária

BPMN - Business Process Modeling Notation

Capes - Coordenação de Aperfeiçoamento de Pessoal de Nível Superior

DM - Dispositivos Médicos

EAS - Estabelecimentos de Assistência a Saúde

EUA - Estados Unidos da América

FDA - U.S. Food and Drug Administration

FAERS - Adverse Event Reporting System

HFE - Human Factors Engineering

IEC - International Electrotechnical Commission

IN - Instrução Normativa

MDDD - Medical Device Design and Development

NBR - Norma Brasileira

NFF - No Fault Found

NOTIVISA - Sistema de Notificação em Vigilância Sanitária

PPHR - Portable Personal Health Record

RSL - Revisão Sistemática da Literatura

SUS - Sistema Único de Saúde

UCD - User-Centred Design

UML - Unified Modeling Language 


\section{INTRODUÇÃO}

Esta introdução ressalta que o sistema de cuidados com a saúde depende da tecnologia médica, e todos os cuidados profissionais também, onde muitos dos Dispositivos Médicos (DM) são desenvolvidos sem a aplicação devida da Engenharia de Usabilidade. E como essas técnicas não estão comumente sendo usadas, os DM’s estão se tornando mais complexos, não intuitivos, de difícil aprendizado e utilização, o que infere um crescimento dos erros de utilização, onde dois terços de todos os eventos adversos relatados poderiam ser prevenidos [2]. Neste contexto de inquietações com os DMs, propõe-se nesta pesquisa em realizar uma Revisão Sistemática da Literatura (RSL) das publicações em Usabilidade de equipamentos médicos.

\subsection{CONTEXTUALIZAÇÃO E FORMULAÇÃO DO PROBLEMA}

Ao longo dos últimos 100 anos, o sistema de saúde depende da tecnologia médica, e o fornecimento desses serviços tem crescido continuamente. Para algumas especialidades, todos os cuidados profissionais dependem da tecnologia, seja na área da medicina preventiva, terapêutica, reabilitação, administração, ou educação e treinamento relacionados a saúde. [3].

Muitos DM's são desenvolvidos sem a aplicação devida da ENGENHARIA DE USABILIDADE, que aplicaria os conhecimentos do comportamento humano na concepção do projeto de um DM, reforçados por testes envolvendo USUÁRIOS, como pacientes, clínicos, pessoal de apoio, leigos, ou qualquer um que interaja com o DM, utilizando ferramentas para atingir a adequada USABILIDADE, seria um meio eficaz de identificar e resolver falhas de projeto. Como essas técnicas não estão comumente sendo usadas, os DM's então se tornando mais complexos, não intuitivos, de difícil aprendizado e utilização, o que infere um crescimento dos ERROS DE UTILIZAÇÃO [4].

Existe a incerteza entre os fabricantes em escolher em que momento deverão iniciar os Teste de Usabilidade, se iniciam na concepção do projeto, na montagem de um protótipo, na sua fabricação ou na sua comercialização. Mas segundoWiklund et al [4], para descobrir perigos relacionados com o uso, se existir algum, será melhor realizar testes em diferentes fases do ciclo de desenvolvimento do produto. Durante os Teste de Usabilidade 
denominados formativos, são realizados testes durante o desenvolvimento de um DM, conforme este evolui a partir de um conceito preliminar para uma solução refinada, ajudando a identificar os pontos fortes e as deficiências do projeto em evolução e confirmar se o projeto está progredindo na direção certa, ou/e poderão ser durante os Teste de Usabilidade definidos como somativos, o qual envolve a avaliação de um projeto de um DM praticamente pronto para a produção, com o objetivo de validar as interações eficazes dos usuários para implementar no processo final de desenvolvimento. Os profissionais especialistas em fatores humanos preconizam a realização de testes: "cedo e frequentemente", e nunca iniciá-los somente quando o DM está a caminho do mercado.

Com essas mesmas preocupações em mente, os organismos internacionais de normas e a literatura acadêmica sugerem a participação do usuário, no denominado Projeto Centrado no Usuário ou UCD (User-Centred Design), através da incorporação de métodos de Engenharia de Fatores Humanos ou HFE (Human Factors Engineering) [5], importante ferramenta do desenvolvimentos de um DM, definida como a aplicação do conhecimento científico nas capacidades e limitações humanas para a concepção de sistemas e equipamentos para produzir produtos com a operação mais eficiente, segura, eficaz e confiável [6].

Neste estudo, analisando as pesquisas, foram realizadas 11 entrevistas com fabricantes de DM's onde foram convidados a responder sobre o papel e o valor que eles acreditavam ter os usuários, dentro do processo de pesquisa e desenvolvimento de DM's, utilizando o Projeto Centrado no Usuário, incorporando métodos de Engenharia de Fatores Humanos [5].

Os resultados revelaram que os fabricantes tenderam a priorizar mais as opiniões dos profissionais de saúde de alto nível hierárquico, procurando para o design e as inovações de projeto de DM's, aqueles indivíduos que tomam decisões de compra, em oposição a consultar os usuários dos dispositivos, pois o foco são as vendas. [5]

Na pesquisa avaliada, responderam que havia pouca motivação com relação à busca de informações junto dos usuários, haja visto que tal prática foi vista pela maioria deles como um ineficiente uso de recursos, e que os usuários tinham um menor nível de influência sobre os EAS (Estabelecimentos de Assistência a Saúde) na especificação e aquisição de seus produtos; outros procuravam os indivíduos que seriam mais influentes na tomada de decisões 
de compra e gostariam de serem competitivos e ágeis dentro de um mercado em ascendente mudanças, e que os resultados dos métodos formais de avaliação não ofereciam esta versatilidade, e como consequência afirmam que esses métodos formais são raramente usados por eles (fabricantes) para o desenvolvimento do DM. Onde apenas um dos 11 fabricantes, afirmou usar regularmente a metodologia de desenvolvimento centrada no usuário, e agrupando os métodos formais de design [5]

Em paralelo com a complexidade funcional, aumenta a preocupação com o projeto e desenvolvimento de novos DM. Surgem preocupações sobre eficácia, segurança e confiabilidade: para serem bem sucedidos, os projetistas e os fabricantes de DM, devem garantir que todos os dispositivos atendam a esses requisitos [6], e enfatizada pela normalização da Engenharia de Usabilidade para produtos para a saúde, pela ABNT IEC NBR 62366.

Essas características são desejáveis para um DM, onde estudos demonstram que para um DM ou serviço ser útil, deve ter os seguintes atributos, ser: Útil, Eficiente, Eficaz, Satisfatório, Fácil de Aprender, e Acessível. Ser Útil, diz respeito ao grau em que um produto permite que um usuário possa alcançar seus objetivos específicos. Obter Eficiência, é a rapidez com que o objetivo do usuário possa ser realizado completamente e com precisão, por exemplo, ao definir um Testes de Usabilidade diria: "95 por cento de todos os usuários serão capazes de carregar o software em 10 minutos". Para ser Eficiente, quando refere-se a medida em que o DM se comporta da maneira com que os usuários esperam, e a facilidade com que os usuários podem usá-lo para executar uma tarefa, ou seja: "95 por cento de todos os usuários serão capazes de carregar o software corretamente na primeira tentativa”. Já a característica de ser Fácil de Aprender, tem relação com a capacidade do usuário de operar o sistema a algum nível definido de competência, após uma certa quantidade de treinamento. Para ser Satisfatório, será quando os entendimentos dos usuários, sentimentos e opiniões sobre o produto, geralmente capturadas através de questionários, atendam às suas necessidades e proporcionem satisfação. E ter Acessibilidade, é ser um produto útil para pessoas com deficiência, ou em qualquer contexto especial, ao simplificar o design elaborando projetos acessíveis [7]. 
Outra preocupação, é a taxa de eventos adversos em pacientes no Brasil, aonde nos destacamos negativamente ao relatar uma maior proporção de eventos evitáveis: dois terços $(66,7 \%)$ dos eventos adversos relatados poderiam ser prevenidos, apresentados em uma pesquisa aplicada em hospitais universitários do Rio de Janeiro [2]. Este resultado foi maior do que a pesquisa analisada em outros países: Nova Zelândia (61,6\%) [8], Austrália (50\%) [9], Inglaterra (52\%) [10], na Dinamarca (40,4\%) [11], França (27,6\%) [12] e Espanha $(42,6 \%)$ [13]. Onde o contraste entre a proporção de eventos adversos evitáveis brasileiros e nesses países.

O Programa Nacional de Segurança do Paciente, apresenta em seu documento de referência, a confirmação da alta incidência de eventos adversos, considerando o Brasil e alguns países, em média $10 \%$ dos pacientes internados sofrem algum tipo de evento adverso e destes $50 \%$ são evitáveis, e que esses problemas podem ser mais frequentes no Brasil do que nos países desenvolvidos [14].

Atualmente, há a percepção de que parte dos eventos adversos relatados mundialmente possui relação direta com erros de utilização de equipamentos médicos, sendo assim poderiam ser prevenidos ou minimizados com a participação do usuário no projeto (usercentered design) através do uso de técnicas de Engenharia de Fatores Humanos ou Engenharia de Usabilidade [15].

Por diversos motivos, seja pelo custo, por terem o foco nas vendas, ou acharem que ouvir o usuário seja uma prática ineficiente de uso de recurso, os fabricantes de DM ainda são relutantes na adoção de métodos formais de inclusão do usuário no projeto: ainda preferem seu desenvolvimento nas indicações de poucos consultores clínicos [16], mesmo com evidências de que médicos como projetistas não são garantias absolutas de um bom produto [17].

No Brasil, cabe a Agência Nacional de Vigilância Sanitária [18] editar normas a fim de determinar, através de Leis, Decretos (DCT), Portarias (PRT), Resoluções da Diretoria Colegiada (RDC) ou Instruções Normativas (IN), ou outra hierarquia legislativa, as normas a serem compulsoriamente obedecidas na certificação de conformidade dos DM. E a ABNT, normalizar a Usabilidade para equipamentos eletromédicos nos termos da norma ABNT NBR IEC 60601-1-6:2011, cuja exigência compulsória foi a partir de dezembro de 2015 (IN 
$n^{\circ}$. 4/2015), e a Usabilidade em software teve sua exigência compulsória iniciada desde julho de 2009 (IN no. 8/2009) até a presente resolução (ANVISA, 2016 .360). E o que se observa, nas pesquisas, é que o Brasil está elaborando escassas publicações que apresentem a aplicação da Engenharia da Usabilidade em seus DMs, indicando, através dos estudos contidos no documento de referência para o Programa Nacional de Segurança do Paciente [4], que o Brasil ainda não se apercebeu do impacto da relação entre eventos adversos relatados e o processo de fabricação de DM.

Neste contexto de inquietações com os DMs e a aplicação da Engenharias de Usabilidade, propõe-se nesta pesquisa em realizar uma Revisão Sistemática da Literatura (RSL) das publicações em Usabilidade de equipamentos médicos, em particular nos aspectos contemplados nas normas: ABNT NBR IEC 60601-1-6:2011, para aplicação da engenharia da usabilidade a produtos para saúde, e da colateral ABNT NBR IEC 60601-1-6, para os Sistemas Eletromédicos Programáveis.

\subsection{OBJETIVOS}

\subsubsection{Objetivo Geral}

O objetivo geral desta pesquisa é realizar uma Revisão Sistemática da Literatura (RSL) publicada em Usabilidade de DM, em particular apresentando a incidência dos resultados dos estudos encontrados nas pesquisas sobre Usabilidade nos Dispositivos Médicos, publicados em periódicos científicos.

\subsubsection{Objetivos específicos}

Este estudo se propõe a elaborar uma triagem nas pesquisas sobre Usabilidade nos Dispositivos Médicos, com o objetivo de responder seis questões:

Questão 1: Onde está sendo a APLICAÇÃO dos estudos em Engenharia de Usabilidade?

Questão 2: Quais os OBJETIVOS DOS ESTUDOS em Engenharia de Usabilidade mais utilizados pelos pesquisadores?

Questão 3: Quais a PRINCIPAIS TÉCNICAS DE USABILIDADE empregadas nos estudos? 
Questão 4: Qual o PÚBLICO-ALVO dos estudos?

Questão 5: Quais as ESPECIALIDADES encontradas nos estudos?

Questão 6: Quais os LOCAIS DE APLICAÇÃO dos estudos?

\subsection{ESTRUTURA DA DISSERTAÇÃO}

No primeiro capítulo teremos uma INTRODUÇÃO, onde apresentamos um diagnóstico das preocupações do crescimento tecnológico dos Dispositivos Médicos, e a falta da aplicação da Engenharia de Usabilidade nos seus desenvolvimentos, gerando erros de utilização, onde também traçamos os OBJETIVOS da pesquisa.

Para o segundo capítulo apresentamos a FUNDAMENTAÇÃO TEÓRICA, onde expomos a normatização que regulamenta a Engenharia da Usabilidade, os conceitos utilizados e os consequentes eventos adversos.

No terceiro capítulo, a METODOLOGIA, definimos os processos de coleta e tratamento de dados, utilizados na RSL. E abaixo de cada uma das seis perguntas científicas a serem respondidas, apresentamos as definições dos subitens avaliados nos estudos. E os textos desses itens, estarão em negrito para não serem confundidos com termos usuais, tais como: Hardware, Questionários, Gerenciamento de Risco, Pacientes, dentre outros.

No quarto capítulo, os RESULTADOS são apresentadas as Tabelas 1, 2, 3, 4, 5 e 6, contendo as ocorrências de cada item pesquisado, respondendo as seis questões. E abaixo dessas tabelas, entre colchetes, encontram-se os números das referências bibliográficas, relacionadas a cada item descoberto nos periódicos pesquisados, que foram apresentadas nas Referências Bibliográficas.

No quinto capítulo a DISCUSSÃO foram expostas as discussões sobre os resultados investigados, considerando cada item de cada tema investigado.

Para o sexto capítulo, apresentamos a CONCLUSÃO dos resultados obtidos na RSL.

E finalizamos com o sétimo capítulo TRABALHOS FUTUROS. 


\section{FUNDAMENTAÇÃO TEÓRICA}

Este capítulo expõe a normatização técnica nacional e internacional vigente, que regulamenta a Engenharia de Usabilidade, e que formalizam novos conceitos e trazem grandes desafios para os fabricantes, desde a concepção do projeto, até a sua comercialização. Define a Engenharia de Usabilidade para os DM, onde se utiliza desta ferramenta, quem vem a ser o usuário e sua influência no design de um DM. Sobre os eventos adversos que as pessoas são vítimas devido aos erros de utilização [2].

\subsection{REGULAMENTAÇÃO DA USABILIDADE}

Paralelo com a tecnologia, vem crescendo também a complexidade funcional e a grande preocupação com o projeto Desenvolvimento de Novos Dispositivos Médicos ou MDDD (Medical Device Design and Development), surgem preocupações sobre eficácia, segurança e confiabilidade. Para ser bem-sucedidos, o projetista e o fabricante de DM, devem garantir que todos os dispositivos atendam a esses requisitos, e atendam as normas nacionais e internacionais [6].

Os dois maiores organismos de normalização e regulação no Brasil para a área de saúde são: a Associação Brasileira de Normas Técnicas (ABNT) e Agência Nacional de Vigilância Sanitária [18].

\subsubsection{ABNT}

A ABNT é responsável pela elaboração das Normas Brasileiras (ABNT NBR), produzidos por seus Comitês Brasileiros (ABNT/CB), Organismos de Normalização Setorial (ABNT/ONS) e Comissões de Estudo Especiais (ABNT/CEE), e atua também na avaliação da conformidade e programas para certificação de produtos, e sistemas e rotulagem ambiental. Onde utiliza a nomenclatura ABNT NBR IEC para identificar as normas brasileiras que possuem compatibilidade com as normas redigidas pela IEC (International Electrotechnical Commission), da qual é membro. Isto é, ela tem a atribuição de apenas normalizar. 


\subsubsection{Anvisa}

A Anvisa, atuando como órgão regulador, e presente em todo Brasil, tem como finalidade "promover a proteção da saúde da população, por intermédio do controle sanitário da produção e consumo de produtos ... inclusive dos ambientes, dos processos, dos insumos e das tecnologias a eles relacionados".

\subsubsection{História da Vigilância Sanitária no Brasil}

As atividades ligadas à Vigilância Sanitária foram estruturadas, nos séculos XVIII e XIX, para evitar a propagação de doenças nos agrupamentos urbanos que estavam surgindo. A execução desta atividade exclusiva do Estado, por meio da polícia sanitária, tinha como finalidade observar o exercício de atividades profissionais, fiscalizar embarcações, cemitérios e áreas de comércio de alimentos [18].

No final do século XIX, com descobertas nos campos de bacteriologia e terapêutica, no período compreendido entre as I e II grandes Guerras Mundiais, houve a necessidade de reestruturação da Vigilância Sanitária [18].

Com o crescimento econômico apresentado no Brasil, as atribuições da VISA cresceram, e os movimentos de reorientação administrativa ampliaram as atribuições da mesma, aferindo evidência ao planejamento centralizado e a participação intensiva da administração pública [18].

No começo da década de 80 , a VISA seguiu o caminho que ela é hoje, e com a participação popular, passou a administrar as atividades concebidas para o Estado, como papel de guardiã dos direitos do consumidor e provedor das condições de saúde da população [19].

E em 26 janeiro de 1999, através da Lei 9.782 é criada a Anvisa - Agência Nacional de Vigilância Sanitária, para cuidar de todas as áreas que lhe foram conferidas [19].

\subsubsection{Hierarquia das Normas}

Para um melhor entendimento da hierarquia das normas da Anvisa, apresentamos abaixo artigo da Constituição Federal, que simplifica esta relação hierárquica. 
Conforme Artigo 59 da Constituição Federal [20]:

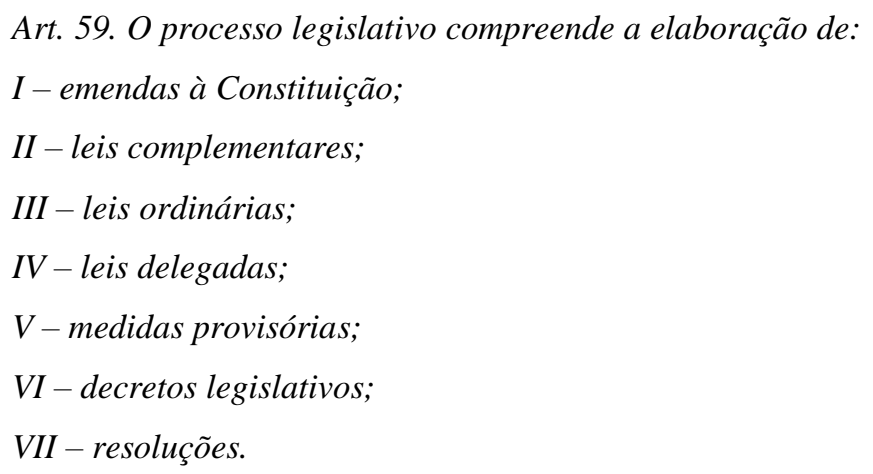

Dentro desta hierarquia, as Normas Constitucionais são as mais importantes no ordenamento jurídico. As Normas Complementares, complementam algumas omissões da Constituição Federal. As Leis Ordinárias, as Medidas Provisórias e Leis Delegadas, estão no mesmo nível hierárquico, porém não há subordinação entre elas. E os Decretos, Portarias e Resoluções são as normas regulamentares, que valem ser definidas [18].

Portaria: instrumento normativo utilizado pelos auxiliares diretos dos chefes de Poder Executivo para regular as atividades de suas pastas.

Instruções Normativas: atos administrativos, expedida por Ministros ou Secretários de Estado, dispondo normas que deverão ser adotadas para o funcionamento do serviço público. Exemplo: IN 4.

Resoluções: deliberações normativas de órgãos colegiados, não podendo extrapolar os limites da lei e da competência do órgão. Exemplo: RDC 59.

A Resolução RDC é elaborada pela Diretoria Colegiada, submetida a consulta pública e então redigida e publicada. Onde, no texto destas resoluções consta o que as subsidiou e quais as outras normas às quais elas estão subordinadas [18].

\subsubsection{Poder Regulamentar da Anvisa}

Em 26 de janeiro de 1999, a Lei 9782 ao ser criada a Anvisa, que nos termos do artigo $8^{\circ}$, é considerada autarquia em regime especial, vinculada ao Ministério as Saúde, tem por finalidade regulamentar, controlar e fiscalizar os produtos e serviços que envolvam riscos à saúde pública. 
Conclui-se, que a Anvisa possui força legal em suas normas. Por exemplo as RDCs, que são retiradas da própria lei federal, e que autoriza esta agência a normatizar as questões relativas à Vigilância Sanitária. Podendo deter atividades que se revelem contrárias, nocivas ou inconvenientes ao bem-estar e à saúde da coletividade, podendo agir com ato de polícia, promovendo a interdição de atividades, apreensão ou destruição de produtos, através de um processo administrativo sanitário.

Os atos regulatórios, cujo contexto se referem às ações normativas sob macrotema "Produtos para Saúde", que vem sendo formuladas pela Anvisa, relacionadas aos Dispositivos Médicos, são apresentados a seguir [21]:

- Lei $\mathbf{n}^{0}$ 6.360/76 e Decreto $\mathbf{n}^{\mathbf{0}} \mathbf{7 9 . 0 9 4 / 7 7}$, determinam que os correlatos necessitam de registro, e as empresas, de autorização para funcionamento, junto ao Ministério da Saúde (MS), com alterações para Lei 13.235/2015, e Lei 13.236/2015, e

- PRT no 04/1986 revogada, PRT no 03/1986 revogada, PRT no 08/1988, revogada $\operatorname{RDC~n}^{\circ} 30 / 2006$, e vigente $\operatorname{RDC~}^{\mathbf{0}} \mathbf{1 5 6 / 2 0 0 6}$, que dispõe sobre o registro, rotulagem e reprocessamento de produtos médicos.

- PRTC SVS/SAS no 01/1996 revogada, PRT SVS no 543/1997 revogada, e dá vigência com alterações à $\mathbf{R D C}^{\mathbf{0}} \mathbf{1 8 5} / \mathbf{2 0 0 1}$, a qual aprova o Regulamento Técnico, que trata do registro, alteração, revalidação e cancelamento do registro de produtos médicos na Anvisa. (Republicada pela RDC n⿳ 207/2006, e alterada pela RDC no 40/2015).

- PRT no 686/1998 revogada, RDC no 59/2000 revogada, RDC no 167/2004, para dá vigência à $\operatorname{RDC~n}^{\mathbf{0}} \mathbf{1 6} / \mathbf{2 0 1 3}$, que aprova o Regulamento Técnico de Boas Práticas de Fabricação de Produtos Médicos e Produtos para Diagnóstico de Uso In Vitro.

- Lei no 9.782/1999, define e cria a Agência Nacional de Vigilância Sanitária.

- RDC $\mathbf{n}^{\mathbf{0}}$ 59/2000, que determina a todos fornecedores de produtos médicos, o cumprimento dos requisitos estabelecidos pelas "Boas Práticas de Fabricação de Produtos Médicos”, revogada pela RDC n⿳ 16/2013, que aprova o Regulamento Técnico de Boas Práticas de Fabricação de Produtos Médicos e Produtos para Diagnóstico de Uso In Vitro. Vigente. 
- RDC no 56/2001, onde os Produtos para a Saúde devem atender aos requisitos essenciais de segurança e eficácia aplicáveis a estes produtos. Vigente.

- $\quad \operatorname{RDC~n}^{\circ}$ 206/2006, revogada, $\operatorname{RDC}^{\circ}$ 61/2011, revogada, para dar vigência à RDC $\mathbf{n}^{\mathbf{0}}$ 36/2015, classificação de risco, os regimes de controle de cadastro e registro e os requisitos de rotulagem e instruções de uso de produtos para diagnóstico in vitro, inclusive seus instrumentos. Vigente.

- $\quad$ RDC n' 52/2007, concessão de autorização de modelo para empresa que atender as disposições legais para registro de seu equipamento, apresentar documento indicando que seu produto encontra em processo de ensaio e certificação no ambito do SBAC. Vigente.

- IN n⿳0 8/2007, revogada, IN n⿳0 3/2011, revogada, e dá vigência à IN n⿳0 8/2009, lista de normas técnicas exigidas para a certificação de equipamentos elétricos sob regime de vigilância sanitária.

- IN $\mathbf{n}^{\mathbf{0}} \mathbf{3 / 2 0 0 8}$, procedimento de análise para realização de alterações de capacidade de equipamentos, alterações de desenho de equipamentos - nível 1 e alterações de excipientes - nível 1. Revogada pela RDC n⿳ 48/2009.

- RDC no 67/2009, normas de Tecnovigilancia aplicáveis aos detentores de registro de produtos para a saúde no Brasil. Vigente.

- $\operatorname{RDC~n}^{\circ}$ 27/2011, e revoga $\mathbf{R D C ~ n}^{\circ}$ 32/2007, que dispõe sobre os procedimentos para certificação compulsória dos equipamentos sob regime de Vigilância Sanitária. Vigente.

- $\operatorname{RDC~n}^{\mathbf{0}} \mathbf{1 5} / \mathbf{2 0 1 2}$, requisitos de Boas Praticas para o processamento de produtos para a saude e dá outras providencias. Vigente.

- $\operatorname{RDC~n}^{\mathbf{0}} \mathbf{1 0 / 2 0 1 5}$, regulamento para a realização de ensaios clínicos com dispositivos médicos no Brasil. Revoga RDC no 39/2008, RDC n⿳36/2012, altera RDC $\mathbf{n}^{\circ}$ 81/2008. Vigente.

- $\mathbf{R D C ~ n}^{\mathbf{0}} \mathbf{4 0 / 2 0 1 5}$, define os requisitos do cadastro de produtos médicos. Vigente com alteração.

- IN $\mathbf{n}^{\mathbf{0}} \mathbf{4} / \mathbf{2 0 1 5}$, aprova a lista de Normas Técnicas, cujos parâmetros devem ser adotados para a certificação de conformidade, no âmbito do Sistema Brasileiro de 
Avaliação da Conformidade (SBAC), dos equipamentos sob regime de Vigilância Sanitária, nos termos da $\mathbf{R D C} \mathbf{n}^{\mathbf{0}} \mathbf{2 7 / 2 0 1 1}$, que revoga a IN no 11/2014. Vigente.

Pode-se observar, que participam inúmeros agentes de regulação no desenvolvimento de um DM, e enfatiza-se que a Anvisa também determina, através da Instrução Normativa IN $n^{\circ} 4 / 2015$, lista das normas a serem compulsoriamente obedecidas na certificação de conformidade dos DM, e através ABNT, a norma geral ABNT NBR IEC 60601-1-1, que possui os requisitos gerais de segurança para equipamentos eletro médicos, seguidas de um conjunto de normas colaterais de finais 60601-1-xx, as particulares de finais 60601-2-xx e as de desempenho 60601-3-xx, também relevantes a MDDD.

Essas normas formalizam novos conceitos que, por sua vez, trazem grandes desafios para os fabricantes nacionais, em relação aos procedimentos durante todo o ciclo de vida de um DM, desde a concepção do projeto, até a sua comercialização. Principalmente com a exigência da Engenharia de Usabilidade, à produtos para saúde, através da ABNT NBR IEC 60601-1-6, importância demonstrada por Shan e Robinson que revisando 25 estudos, relataram e confirmam que o envolvimento dos usuários no MDDD obtém benefícios significativos, como fonte de geração de idéias para novos produtos, redução dos custos de desenvolvimento, como reformulações, identificação de deficiências conceituais, melhorias nas interfaces com o usuário, na funcionalidade, na eficácia, na Usabilidade e qualidade de DM [22].

\subsection{DEFINIÇÕES}

Segundo a ABNT NBR IEC 62366 [23], nota-se uma cadeia que inicia-se com a ENGENHARIA DE USABILIDADE, que aplica os conhecimentos sobre o comportamento humano, habilidades, limitações e outras características humanas relacionadas ao projeto de ferramentas, produtos, sistemas, tarefas, trabalho e ambientes, na concepção do projeto de um DM, reforçados por testes envolvendo USUÁRIOS, definidos como pacientes, clínicos, pessoal de apoio, leigos, ou qualquer um que interaja com o DM, ou pessoa utilizando, operando ou manuseando o PRODUTOS PARA A SAÚDE, consistindo em qualquer instrumento, aparato, implemento, máquina, dispositivo, implate, calibrador ou reagente in vitro, software, material ou outro artigo similar ou relacionado, com intenção do fabricante 
para ser utilizado, combinado ou isoladamente, em serem humanos visitando um ou mais específicos propósitos, utilizando ferramentas para atingir a adequada USABILIDADE, que seria um meio eficaz de identificar e resolver falhas de projeto, sendo uma característica da INTERFACE DE USUÁRIOS, meios pelos quais o USUÁRIO e o PRODUTOS PARA A SAÚDE interagem, a fim de estabelecer EFETIVIDADE (medida do grau de quanto os USUÁRIOS conseguem atingir as metas especificadas), EFICIÊNCIA (Efetividade em relação aos recursos despendidos), facilidade de uso e satisfação, finalmente do USUÁRIO.

De acordo com Vincent [15], na União Europeia, a inserção no mercado de Dispositivos Médicos é regida por uma série de diretivas, onde ao fabricante deste DM seja exigido: "redução, tanto quanto possível, dos riscos de erros de utilização devido às características de ERGONOMIA do dispositivo e do ambiente", onde "eles (os DM) devem considerar: “conhecimentos técnicos, experiência, educação e formação, aplicável as condições médicas e físicas dos usuários pretendidos".

Estudos apresentam a relação entre ERGONOMIA e FATORES HUMANOS (HFE), e que sugere que deve desempenhar um papel mais relevante nos cuidados da saúde, a fim de aumentar a consonância em melhorar a segurança do paciente. Onde estes especialistas, estudam as interações entre as pessoas e os elementos do sistema em que trabalham (ambiente físico, tarefas, ferramentas, tecnologias), considerando todas estas interações com o objetivo de otimizar de forma conjunta, os elementos sociais e técnicos, e se concentrando no design de interfaces amigáveis que podem melhorar o desempenho do usuário, e reduzir o erro humano. Onde o HFE é composto por três especialidades: 1) ERGONOMIA FÍSICA: identifica as forças físicas e limitações dos seres humanos, e planejam ambientes de trabalho, considerando essas características físicas. Por exemplo: projetar um espaço clínico que reduzir o tempo de transporte de pacientes no pós-operatório da sala de cirurgia para a unidade terapia intensiva; 2) ERGONOMIA COGNITIVA: agrupam as habilidades cognitivas e limitações de seus usuários. Por exemplo: identificar as causas de falhas de comunicação em um trabalho de equipe, implementando soluções; e 3) MACROERGONOMIA: que lida com a concepção do sistema de trabalho, considerando as interações entre componentes diferentes do sistema. Por exemplo: compreender e analisar um sistema da Emergência, para identificar potenciais riscos ou investigar a causas de eventos adversos a fim de projetar e implementar soluções eficazes. E ao analisar a 
integração Engonomia e HFE, sugere as seguintes medidas no esforço de melhorias dos resultados desta relação: 1) Capacitar e educação continuada, dos médicos, enfermeiros, cuidadores, administradores e outros profissionais de saúde, para entendimento das ferramentas; 2) Promover projetos de melhorias da segurança do paciente, aplicando os princípios em conjunto com os estudantes de medicina; 3) Elaborar programs de pósgraduação para produzir um maior número de profissionais qualificados; e 4) Expandir investimentos aos esforços de melhorias na segurança do paciente [24].

\subsection{BENEFÍCIOS}

Diferente áreas da Engenharia, em particular as que envolvem sistemas críticos e/ou com alto grau de iteração com o usuário, já incorporaram práticas da Usabilidade em seus projetos, e têm se mostrado eficazes, seja no desenvolvimento de sistemas de computador altamente complexos dada a importância do ser humano no circuito em sistemas de aviação, na evolução dos controles de interfaces na cabine de vôo e nas estações de trabalho de controle de tráfego aéreo comerciais, apresentados por [25]; para o desenvolvimento de sistemas de telemedicina, abordando a engenharia de fatores humanos baseados nas análises de tarefas realizadas pelo usuário, para entender e documentar a interação entre as suas atividades de trabalho e um sistema, [26]; e para os engenheiros de software que devem considerar a Usabilidade como um atributo de qualidade em seus projetos de arquitetura determinando como efetivamente e confortavelmente um usuário final pode alcançar os objetivos que deram origem a um sistema interativo na visão de [27]. Todas essas e outras práticas necessitam, contudo, serem adaptadas às especificidades do processo de desenvolvimento da tecnologia médica [4].

Os Teste de Usabilidade tem muitos beneficiários: para os Fabricantes dos DM, com as melhorias de design pode-se aumentar as vendas, a fidelização de clientes e a redução da demanda no atendimento ao cliente; para os Clientes como hospitais e clínicas, obtém-se trabalhadores mais produtivos, redução nos custos de treinamento e melhorias no atendimento ao paciente; para os Cuidadores como médicos, enfermeiros, terapeutas, dentre outros, obtém-se melhorias no projeto que são susceptíveis de fazer um DM mais fácil de aprender a usar; e finalmente e mais importante, para os Pacientes, os Teste de Usabilidade 
reduzem a propensão de que eles sejam feridos ou cheguem a óbito por falhas de interface de usuário. [4].

\subsection{HISTÓRICO}

Fazendo uma retrospectiva, e analisando a evolução da Usabilidade no mundo, podemos observar que:

- A Usabilidade existe a mais de 100 anos [28];

- Como a conhecemos hoje, iniciou-se na década de 80 [28];

- 1996, o FDA infere a necessidade de Teste de Usabilidade, sem usar o termo, em uma revista de regulamentação [4];

- 1996, surge a IEC 60601-1-6 Sistemas Eletromédicos Programáveis;

- 2001, a ANSI e a AAMI divulgaram ANSI/AAMI HE74/2001 - Fatores Humanos no Processo de Design dos Dispositivos Médicos [4];

- 2004, publicada IEC 60601-1-6: Equipamentos Elétricos Médicos - Normas de segurança: Usabilidade [4];

- 2007, a IEC 62366:2007 Dispositivos Médicos - Aplicação de Engenharia de Usabilidade para Dispositivos Médicos [4];

- 2009, a IEC 60601-1-6 Sistemas Eletromédicos Programáveis passa a ser compulsória no Brasil;

- 2010, a ABNT adiciona ao seu catálogo das normas brasileiras, a IEC 62366 [23] .

No Brasil, a Anvisa também sem usar o termo Usabilidade, determina através de outros dispositivos reguladores, por intermédio do Ministério da Saúde (MS) inicia em 1998, pela Portaria SVS n⿳ 686, de 27/08/1998, onde o MS internaliza a Resolução Mercosul GMC $n^{\circ}$ 65/96, que estabelece os requisitos para as Boas Práticas de Fabricação e Controle em Estabelecimentos de Produtos para Diagnóstico de Uso "in-vitro". Onde, na Anvisa passa a

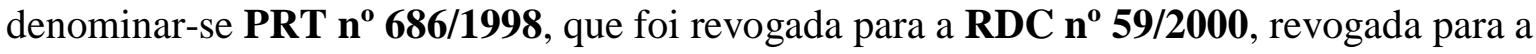
RDC $\mathbf{n}^{\mathbf{0}} \mathbf{1 6 7 / 2 0 0 4}$, e vigente com as devidas atualizações para a $\operatorname{RDC} \mathbf{n}^{\mathbf{0}} \mathbf{1 6} / \mathbf{2 0 1 3}$, através da qual determina-se que os fornecedores de DM cumpram requisidos para "Boas Práticas de Fabricação de Produtos Médicos". E que vai acontecendo em outros dispositivos legais, conforme apresentados no item anterior sobre os regulamentos da Anvisa. 


\subsection{EVENTOS ADVERSOS}

A razão mais profunda para conduzir Testes de Usabilidade de DM, de acordo com [4], é também proteger pessoas de eventos adversos, como ferimentos, óbitos, ou falsos diagnósticos, devido aos erros de utilização, porque alguém acionou inadvertidamente um botão, ou especificou erradamente um parâmetro, ou utilizou uma sequência incorreta, ou ignorou uma mensagem de alarme, enquanto se utiliza um DM. E o Teste de Usabilidade e a Engenharia de Usabilidade, podem oferecer aos fabricantes, no mínimo, uma proteção de responsabilidade, defendendo-o contra alegações de que não seguiram as melhores práticas de fabricação, bem como melhorias no seu processo de desenvolvimento. Por outro lado, os fabricantes que não realizam Testes de Usabilidade no curso de desenvolvimento de um DM poderia ser acusado de negligência. Portanto, Testes de Usabilidade devem ser considerados imperativos, bem como uma exigência regulamentar de fato.

Milhares de pessoas são vítimas de eventos adversos sérios (Serious Adverses Events): morte, hospitalização, risco de vida, falsos diagnósticos ou outras consequências graves, a cada ano, devido a Erros de Utilização que envolvem DMs, que podem ser desde um termômetro, até um sistema de captação de imagens. [29]. Erros como, pressionar um botão errado ou programar erroneamente uma bomba de infusão, por exemplo, digitando o número 80 (oitenta) em vez de 8,0 levaram a tantas mortes que a indústria americana criou a expressão "death by decimal" (morte por decimal) [4].

A aplicação da Engenharia de Usabilidade ou Engenharia de Fatores Humanos e Testes de Usabilidade no desenvolvimento de DM, ajudam a reduzir as taxas de Erros de Utilização, e limitam os riscos associados ao uso, obtendo mais segurança aos usuários [4], [14], [24].

Nos Estados Unidos (EUA), através do FDA (U.S. Food and Drug Administration) que emite relatórios de estatísticas definidos especificamente de Eventos Adversos, ou FAERS (Adverse Event Reporting System), publicou dados recebidos de pacientes nos últimos dez anos, e obtiveram em 2013 o número de 711.232 (setecentos e onze mil, duzentos e trinta e dois) notificações de Eventos Adversos [29].

No Brasil, através de Relatórios da NOTIVISA, o Sistema de Notificação em Vigilância Sanitária apresentou 18.345 notificações de Eventos Adversos, no ano de 2013. [30] Embora pareçam números elevados, os eventos contidos neste relatório não refletem a totalidade real de casos, pois é alta a incidência de subnotificação. 
Para alguns estudos, não há justificativa científica aceitável para entender porque os Eventos Adversos ocorrem, como os pacientes são prejudicados, e quais os danos relacionados a ele. Tem-se a certeza, que existe a necessidade de investigações, mesmo que os recursos para sua manutenção sejam insuficientes. [31]

Os EAS devem possuir uma sistemática de monitorização e gerenciamento de riscos relacionados ao uso das tecnologias, aproveitando-se da rastreabilidade dessas tecnologias, a fim de utilizar estes dados na escolha das tecnologias a serem adquiridas. [32]

A norma que trata de riscos em dispositivos médicos, é NBR ISO 31000/2009 que destaca que gerir riscos é um processo que tem como fundamentos a aplicação sistemática de políticas, procedimentos e práticas de gestão para as atividades de comunicação, consulta, estabelecimento do contexto, e na identificação, análise, avaliação, tratamento, monitoramento e análise crítica dos riscos.

O gerenciamento de risco é particularmente importante aos produtos para a saúde, devido à pluraridade de partes interessadas: profissionais de saúde, indústrias, governos, pacientes, e o público em geral. Onde, a percepção do risco pode variar muito, dependendo: da formação cultural, socioeconômica e educacional deste público; do estado de saúde do paciente e muitos outros fatores. Assim, partindo da hipótese de que cada parte interessada possui distintas percepções a respeito do risco e, consequente distintos graus de leituras do risco, pode-se concluir que contribuem para o aumento da complexidade da gestão de risco no contexto de uma organização de saúde. [32]

Para minimizar estes riscos, os organismos internacionais de normalização criaram Testes de Usabilidade sem existir ainda uma exigência legal. Como resultado, os Testes de Usabilidade tornaram-se um procedimento operacional padrão entre os fabricantes que desenvolviam DM sem explicitamente serem exigidos por qualquer governo, mas já era altamente recomendável. [4].

Neste contexto de inquietações com os DMs e sua Usabilidade, este trabalho buscou realizar uma Revisão Sistemática da Literatura (RSL) publicada em Usabilidade de equipamentos médicos, onde está sendo sua Aplicação, quais seus Objetivos desses estudos, as Técnicas empregadas, o Público Alvo, as Especialidades, e em quais Locais estão sendo aplicados, na avaliação dos DM por meio da Usabilidade. 


\section{METODOLOGIA}

Esse capítulo apresenta os processos empregados para coleta e tratamento dos dados, utilizando-se de uma Revisão Sistemática de Literatura (RSL), com objetivo de identificar dados de estudos sobre Usabilidade em DM, a partir de critérios instituídos pelo pesquisador, através de um metabuscador de periódicos, para a triagem foram definidos critérios de inclusão e exclusão dos artigos, afim de responder seis perguntas.

\subsection{A PESQUISA}

Esta pesquisa consiste em uma Revisão Sistemática da Literatura (RSL), que foi originalmente aplicada na medicina, e reconhecida como um dos componentes para lidar com a pesquisa baseada em evidências, inspirada pelo sucesso nas áreas da economia, psicologia, ciência social, engenharia de software, dentre outros temas de interesse. [33] E que tem como objetivo identificar, reunir e avaliar de maneira crítica e sistemática dados de estudos primários que rebatam a uma mesma questão científica, onde deve ser feita uma análise seletiva dos dados e disponibilizada em uma síntese imparcial, reprodutível e atualizada das melhores evidências encontradas [34].

\subsection{BUSCA DOS ARTIGOS CIENTÍFICOS}

Para esta RSL, foi utilizado um meta buscador, sistema capaz de fazer buscas simultaneamente em várias bases de dados e sites de busca, disponibilizado pela Coordenação de Aperfeiçoamento de Pessoal de Nível Superior, biblioteca virtual a qual reúne produções científicas de pesquisas nacionais e internacionais, nos fornecendo a centralização de um maior número de bases de dados em um mesmo ambiente de busca, possuindo um acervo de mais de 37 mil títulos com texto completo, 126 bases referenciais, 11 bases dedicadas exclusivamente a patentes, além de livros, enciclopédias e obras de referência, normas técnicas, estatísticas e conteúdo audiovisual.

A pesquisa iniciou-se em novembro de 2015, onde a estratégia de busca inicial foi realizada utilizando o campo de "pesquisa avançada", combinando as palavras chaves Usability, e utilizando o operador AND com a palavra-chave Medical Device, onde retornaram 25.051 periódicos, e filtrando-os nas línguas português, inglês e espanhol. 


\subsection{SELEÇÃO DOS ARTIGOS}

\subsubsection{Critérios de Inclusão}

Para os critérios de inclusão, como os artigos em português geraram apenas três de resultados, e espanhol sete. E para um melhor refinamento das ocorrências, foi incluído apenas a língua inglesa.

Foram elencadas as seguintes bases de dados: Scopus (Elsevier), Science Citation Index Expanded (Web of Science), ProQuest Advanced Technologies \& Aerospace Collection, OneFile (GALE), Technology Research Database, Advanced Technologies Database with Aerospace, MEDLINE/PubMed (NLM), Computer and Information Systems Abstracts, Social Sciences Citation Index (Web of Science), SciVerse ScienceDirect (Elsevier), Engineering Research Database, Directory of Open Access Journals (DOAJ), SpringerLink, Electronics and Communications Abstracts, Wiley Online Library, ERIC (U.S. Dept. of Education), Mechanical \& Transportation Engineering Abstracts, ACM Digital Library, Sage Publications (CrossRef), SAGE Journals.

\subsubsection{Critérios de Exclusão}

O critério inicial de exclusão foi temporal: a limitação aos últimos 10 anos de publicações. Em seguida, foram desconsiderados todos os recursos distintos de artigos em periódicos científicos, não pertinentes ao estudo: Resenhas, Artigo de Jornal, Ata de Congresso, Recursos Textuais e Sites Web; e temas versados em outras áreas de conhecimentos, além da engenharia biomédica, como: Bioinformatic, Rehability, Data Processing, Software e Telemedicine.

Após a aplicação destes critérios, restaram 259 (duzentos e cinquenta e nove) artigos potencialmente relevantes, todos em língua inglesa. E através da análise de títulos, abstracts, foram eliminados 63 (sessenta e três) duplicatas e artigos fora do tema, restando 196 (cento e noventa e seis) periódicos. Dos restantes, outros 51 estavam indisponíveis, finalizando 144 (cento e quarenta e quatro) estudos para análise final, conforme fluxograma apresentado na Figura 1. 


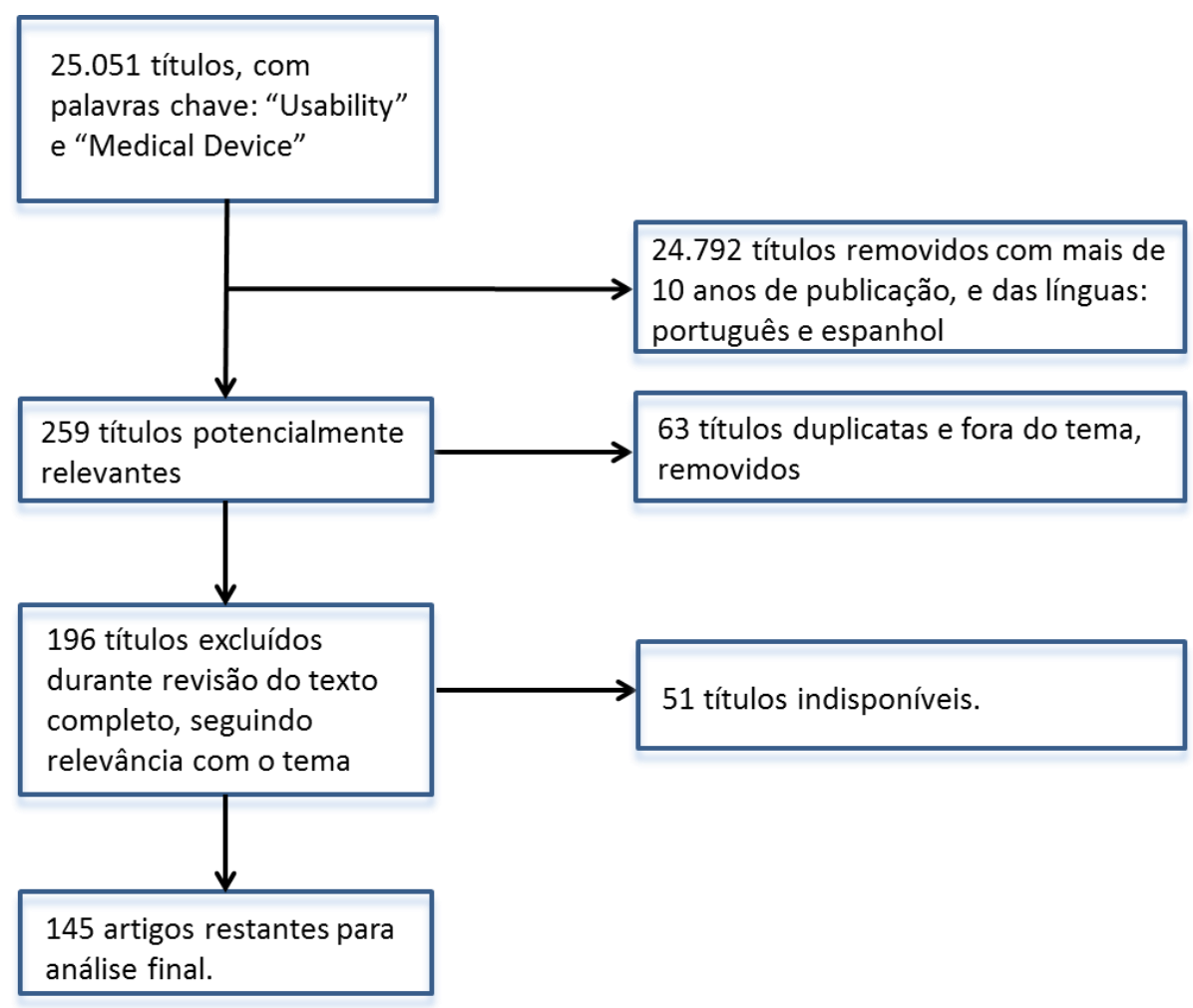

Figura 1: Fluxograma dos resultados do processo de triagem para a revisão sistemática

\subsection{AS PERGUNTAS}

Este estudo se propõe a elaborar uma seleção dentro das pesquisas sobre Usabilidade nos Dispositivos Médicos, com o objetivo de responder a seis questões. Onde, abaixo de cada uma das perguntas, estarão dispostas as definições dos subitens avaliados nos estudos.

\subsubsection{QUESTÃO 1: Onde está sendo a APLICAÇÃO dos estudos em Engenharia De Usabilidade}

- Hardware: no crivo da pesquisa, foi considerado como fazendo parte do grupo Hardware, os estudos onde houve a aplicação da avaliação de Usabilidade diretamente no conjunto de peças, maquinaria, ou parte física do DM.

- Software: foi considerado como fazendo parte do grupo Software, quando o estudo praticou a aplicação da avaliação de Usabilidade no conjunto de instruções e programas utilizados durante o uso do DM.

- Processos: quando a pesquisa praticou o uso da avaliação de Usabilidade nos Processos do DM, na realização de operações, das técnicas ou métodos no uso do 
DM. Processo pode ser definido por [35], como uma sequência de passos e medidas tomadas para atingir um fim particular. Exemplo: os processos são a sequência de passos dados para fazer uma consulta médica ou uma sequência de atividades realizadas para desenvolver um novo produto, ou mesmo a sequência de etapas para produzir uma ação em um DM.

\subsubsection{QUESTÃO 2: Quais os OBJETIVOS DOS ESTUDOS em Engenharia de Usabilidade mais utilizados pelos pesquisadores?}

Definiremos a seguir a significado de cada item avaliado na Questão 2.

- Gerenciamento de Risco: na triagem da pesquisa, foi considerado Gerenciamento de Risco, o estudo onde houve a aplicação de procedimentos de análise, avaliação, controle e monitoração de risco, e/ou quando esta aplicação pode afetar a segurança, a saúde humana, ou a integridade profissional, de acordo com a Anvisa. (ANVISA/ NBR ISO 14971:2009).

- Gerenciamento de Falhas: quando o estudo perpetrou uso do Gerenciamento de Falhas, o fez através do controle de riscos, identificando as possibilidades de falhas com o objetivo de eliminá-las, reduzindo sua frequência ou neutralizando seus efeitos. (CARDELLA, 1999).

- Desenvolvimento de Produto (Formativo): os testes foram executados no DM na fase do Desenvolvimento do Produto. E observa-se, que os pesquisadores respondem aos fabricantes de DM, quando necessitam decidir em que momento deverão iniciar os Teste de Usabilidade, se irão iniciar na concepção do projeto, na montagem de um protótipo, na sua fabricação ou na sua comercialização, segundo (WIKLUND et al., 2011), para descobrir perigos relacionados com o uso, se existir algum, será melhor realizar testes em diferentes fases do ciclo de desenvolvimento do produto. Durante os Teste de Usabilidade, a avaliação do produto denominada Formativos, são realizados testes durante a formação de um DM, conforme este evolui a partir de um conceito preliminar para uma solução refinada, ajudando a identificar os pontos fortes e as deficiências do projeto em evolução e confirmar se o projeto está progredindo na direção certa. 
- Avaliação de Produto (Somativo): quando avaliação dos Teste de Usabilidade, são aplicados praticamente com DM pronto para a produção, são denominados de Somativo, com o objetivo de validar as interações eficazes dos usuários para implementar no processo final de desenvolvimento. [4]

- Testes Clínicos/Experimentais: para as atividades dos testes onde foram executados dentro de ambientes, como salas de enfermagem, quartos, simuladores médicos, ou até em ambientes clínicos reais, enquanto são observados, afim de determinar como o DM facilita ou dificulta a conclusão da tarefa pelo usuário, documentando erros de uso, podendo gravar os dados, tempos de tarefa, comentários dos participantes do teste, dentre outras formas de avaliação. (WIKLUND et al., 2011)

- Educação, Capacitação, Treinamento: quando o estudo praticou Educação, Capacitação, ou Treinamento durante os testes dos DM, com a preocupação com o treinamento dos usuários, o que provoca, segundo [36], um impacto mais imediato sobre o uso seguro e eficaz desses DM.

\subsubsection{QUESTÃO 3: Quais as principais TÉCNICAS DE USABILIDADE empregadas nos estudos?}

- Questionários: neste, a técnica utilizada na avaliação do DM, foi o Questionário, onde foram coletados dados sobre o DM de forma coletiva ou individual, respondidas pelos usuários sem a intervenção de um interlocutor.

- Entrevistas: para coleta e análise dos dados, foram aplicadas Entrevistas, durante as quais são respondidas perguntas feitas por avaliadores, com o objetivo de identificar possíveis falhas nas interações dos usuários com o DM.

- Simulação de Cenários: quando os testes foram conduzidos através de Simulação de Cenários, ou Ambientes Clínicos Simulados, no EAS ou em laboratório, onde os administradores dos testes podem, por exemplo, dirigir as atividades de dentro de uma sala, observando o usuário a partir de uma sala adjacente através de um espelho de sentido único, ou também podem ser elaborados em ambientes como salas de enfermagem, salas de conferências, quartos, simuladores médicos, ou até em ambiente clínico real, seja através de um protótipo, ou um modelo equivalente ao dispositivo comercial. (WIKLUND et al., 2011) 
- Engenharia de Fatores Humanos: foram encontrados nos estudos a aplicação da Engenharia de Fatores Humanos nos Teste de Usabilidade, com a aplicação do conhecimento científico através das capacidades e limitações humanas, para a concepção de sistemas e equipamentos, a fim de produzir produtos com a operação mais eficiente, segura, eficaz e confiável. [6]

- Heurísticas: quando são aplicadas as Heurísticas, método que tem sido tradicionalmente usado para avaliar sites, bem como áreas de trabalho, aplicações de software, afim de apontar as dificuldades de interface de software, e foi adaptado por [37] para DM, e podem revelar problemas de Usabilidade, onde os avaliadores aplicam um conjunto de heurísticas de Usabilidade para um DM, a fim de identificar violações dessas heurísticas, e computar a gravidade da cada violação.

- Interação Homem-Máquina: foram encontrados nestes estudos, a técnica de Interação Homem-Máquina, que avalia o DM através da avaliação dificuldades na execução das tarefas, devido a interação usuário e DM, fazendo uma análise crítica de onde poderá ser otimizado, como acontecerá a sua evolução, do ponto de vista do (dos usuários) médico, do paciente, e do fabricante, conforme metodologia combinada Combined Cognitive and Physical Evaluation (CCPE), metodologia analítica que busca de forma conjunta as potenciais deficiências na interação homem-máquina, proposta por (BLIGARD, 2014), combinando avaliação cognitiva e física, a Ergonomia Física e a Engenharia de Fatores Humanos.

- Análise de tarefas: nas pesquisas onde foram aplicadas esta técnica, selecionaram e classificaram as tarefas, de acordo com as suas especificações e descrições, fazendo sua análise do DM através de diferentes testes, também fazendo parte da metodologia CCPE. (BLIGARD, 2014)

- Grupos focais: foi aplicada nos estudos esta técnica de pesquisa que coleta dados por meio das interações grupais, ao se discutir um tema sugerido pelo pesquisador, são uma forma popular de coleta de dados qualitativos, e pode ser definida como uma forma particular de entrevistar e explorar um grupo dinâmico, apontando experiências e perspectivas das pessoas no contexto pesquisado [38]

- Análise Cognitiva: avaliação das potenciais deficiências de tarefas na interação homem-máquina, e faz uma analise crítica de onde poderá ser otimizado, como 
acontecerá a sua evolução, do ponto de vista do dos usuários, do médico, do paciente, e do fabricante. (BLIGARD, 2014)

- Outros: quando não foi indicado qual técnica aplicada, e unimos às técnicas menos pontuadas: Narração (Storytelling) e Taxonomia de Erro Humano, que obtiveram apenas um periódico cada.

\subsubsection{QUESTÃ̃ 4: Qual o PÚBLICO-ALVO dos estudos?}

- Pacientes ou usuários leigos: quando foi definido na pesquisa, que o tipo de público alvo na pesquisa era o usuário;

- Sem restrição: dentro desta classificação, foi subdividida quando o público alvo da pesquisa, era apenas pacientes leigos;

- Pacientes Deficientes ou Idosos: o público alvo da pesquisa eram Pacientes Deficientes ou Idosos;

- Enfermeiros: o público alvo da pesquisa eram Enfermeiros;

- Médicos/Residentes: o público alvo da pesquisa era Médicos/Residentes;

- Técnicos/Auxiliares/Estudantes: neste caso, o público alvo da pesquisa era Técnicos/Auxiliares/Estudantes;

- Não especificado: neste caso, quando não foi definido o tipo de usuário alvo na pesquisa;

\subsubsection{QUESTÃO 5: Quais as ESPECIALIDADES encontradas nos estudos?}

Em relação as especialidades, ou área de atuação do estudo de Usabilidade (ordem de resultados).

- Gastroenterologia;

- Imagens/Medicina Nuclear;

- Anestesiologia;

- Fisioterapia/Reabilitação;

- Respiratória/Pulmonar;

- Diagnóstico;

- Endócrinologia; 
- Neurologia;

- Urologia;

- Cardiovascular;

- Nefrologia;

- Oftalmologia;

- Oncologia;

- Ortopedia/Geriatria/Reumatologia;

- Dermatologia;

- Hematologia;

- Odontologia;

- Veterinária.

\subsubsection{QUESTÃO 6: Quais os LOCAIS DE APLICAÇÃO dos estudos?}

Em relação a localização do Dispositivo Médico no EAS.

- EAS (Estabelecimento de Assistência a Saúde): quando não foi definido o local exato da pesquisa, denominamos de EAS;

- Ambulatório: quando o estudo aplicou sua avaliação de Usabilidade no Ambulatório.

- Laboratório de Análises Clínicas: se os estudos aplicaram seus testes no Laboratório de Análises Clinicas;

- Homecare: quando os estudos foram localizados na avaliação do tratamento dos usuários em casa;

- Emergência/Pronto Socorro: essas localizações foram concentradas em um mesmo item;

- Telemedicina: quando os estudos foram aplicados no atendimento à distância;

- Cirurgia/Cuidados Intensivos: foram concentrados em um mesmo item;

- Laboratório de Eletrônica/Automação: pela similaridade de atuação, foram concentrados em um mesmo item; e 


\subsection{ANÁLISE ESTATÍSTICA}

O método estatístico ANOVA, o qual testa a hipótese de que três ou mais populações QUE tenham a mesma média [39], foi utilizado como recurso, para examinar os domínios Hardware (HW), Software (SW) ou Processos (PR), e suas superposições SW + PR, $\mathbf{H W + S W}, \mathbf{H W}+\mathbf{P R}$ e $\mathbf{H W + S W + P R}$, através da análise dos tempos médios de suas publicações, e a quantidade de trabalhos divulgados, dentro da faixa de tempo pesquisada (10 anos), a fim de verificar se existe um intervalo significativo entre os tempos médios dos artigos pesquisados.

\subsection{COLETA E ANÁLISE DE DADOS}

Nesta pesquisa, a metodologia empregada na coleta e tratamento de dados utiliza uma abordagem qualitativa e quantitativa, através de uma Revisão Sistemática de Literatura (RSL), onde os dados foram coletados de acordo com as varáveis escolhidas, para responder as seis questões que serão analisadas, onde estes dados foram dispostos em tabelas apresentadas a seguir. 


\section{RESULTADOS}

Neste capítulo, serão apresentados os resultados, os quais estão detalhados nas Tabelas 1, 2, $3,4,5$, e 6 abaixo, respondendo às seis questões, relacionadas aos objetivos do estudo, ressaltando os escopos comuns encontrados nas referências bibliográficas.

\subsection{EVIDÊNCIAS DESCOBERTAS}

Para cada questão a ser respondida, corresponde um conjunto de dados agrupados, onde dos 196 (cento e noventa e seis) títulos totais pesquisados, para responder a Questão 1, foram validados e avaliados 144 (cento e quarenta e quatro) periódicos; para a Questão 2, foram validados todos os 196 (cento e noventa e seis); para Questão 3 foram 196 (duzentos); a Questão 4 são 148 (cento e quarenta e oito); na Questão 5 foram 54 (cinquenta e quatro); e para Questão 6 foram 75 (setenta e cinco); de acordo com suas especificidades.

\subsubsection{QUESTÃo 1: Onde está sendo a APLICAÇÃO dos estudos em engenharia de usabilidade?}

Os resultados estão descritos na Tabela 1: na horizontal estão os subtotais parciais de cada item quantificado; na vertical, estão listados os totais, onde encontramos o total geral de 144 (cento e quarenta e cinco) periódicos científicos encontrados.

Assim respondendo à Questão 1, é possível perceber que 49\% (70 de 144) dos artigos estavam relacionados à Usabilidade aplicadas ao Hardware denominado Apenas Hardware, e 14,5\% (21 de 144) estavam relacionados apenas à Usabilidade em Software (Apenas Software) dos dispositivos médicos. Cerca de 6,9\% (10 de 144) dos artigos aplicaram Usabilidade para Processos envolvendo DM. Somente 2,1\% (3 de 144) dos artigos revisados avaliaram Software e Processos concomitantemente. Este é um número muito menor do que os que avaliaram outras superposições: Hardware e Software, 11 de 144 (7,6\%); Hardware e Processos, 6 de $144(4,1 \%)$ e Hardware, Software e Processos, 1 de $144(0,7 \%)$. 
Tabela 1: Resultados da triagem: APLICAÇÃO de Usabilidade

\begin{tabular}{|c|c|c|c|c|}
\hline & HARDWARE & SOFTWARE & PROCESSOS & $\begin{array}{c}\text { Sub } \\
\text { Total } \\
\text { Parcial }\end{array}$ \\
\hline Apenas Hardware & $49 \%$ & & & 70 \\
\hline Apenas Software & & $14,5 \%$ & & 21 \\
\hline Apenas Processos & & & $6,9 \%$ & 10 \\
\hline Software e Processos & & $2,1 \%$ & $2,1 \%$ & 3 \\
\hline Hardware e Software & $7,6 \%$ & $7,6 \%$ & & 11 \\
\hline Hardware e Processos & $4,1 \%$ & & $4,1 \%$ & 6 \\
\hline $\begin{array}{l}\text { Hardware, Software e } \\
\text { Processos }\end{array}$ & $0,7 \%$ & $0,7 \%$ & $0,7 \%$ & 1 \\
\hline Total Geral & 88 & 36 & 20 & \\
\hline 144 & $61 \%$ & $25 \%$ & $14 \%$ & \\
\hline
\end{tabular}

\section{Referências:}

Apenas Hardware: [40], [41], [42], [43], [44], [45], [46], [47], [48], [49], [50], [51], [52], [53], [54], [55], [56], [57], [58], [59], [60], [61], [62], [63], [64], [65], [66], [67], [68], [69], [70], [71], [72], [73], [74], [75], [76], [77], [78], [79], [80], [81], [82], [83], [84], [85], [86], [87], [88], [89], [90], [91], [92], [93], [94], [95], [96], [97], [98], [99], [100], [101], [102], [103], [104], [105], [106], [107], [108], [109].

Apenas Software: [110], [111], [112], [113], [114], [115], [116], [117], [118], [119], [120], [121], [122], [123], [124], [125], [126], [127], [128], [129], [130].

Apenas Processo: [131], [132], [133], [134], [135], [136], [137], [138], [139], [140].

Software e Processo: [141], [142], [143].

Hardware e Software: [144], [1], [145], [146],[147], [148], [149], [150], [151], [152], [153].

Hardware e Processo: [154], [155], [156], [157], [158], [159].

Hardware, Software e Processo: [160]. 


\subsubsection{QUESTÃO 2: Quais os OBJETIVOS dos estudos em engenharia de usabilidade}

mais utilizados pelos pesquisadores?

Avaliando a Questão 2, obtivemos os resultados exibidos na Tabela 2, e avaliando em pares algumas categorias semelhantes, como Avaliação do Produto (Somativo) e

Desenvolvimento do Produto (Formativo), quando os testes são efetuados somente após fabricação dos DM, obteve 32,1\% (63 de 196), e cerca de 22,4\% (44 de 196) dos artigos aplicaram Usabilidade nos DM, respectivamente.

E foram aplicados Testes Clínicos Experimentais nos DM em 28,6\% (56 de 196) periódicos.

Para o par Gerenciamento de Risco e Gerenciamento de Falhas, foram respectivamente $6,6 \%$ (13 de 196) e 6,1\% (12 de 196), dos artigos analisados que aplicaram esta categoria na avaliação dos DMs.

E houveram apenas 8 de 196 (4,1\%) que utilizaram ferramentas de Educação, Capacitação ou Treinamento na aplicação da Engenharia de Usabilidade dos DM.

Tabela 2: Resultados da triagem: OBJETIVOS dos estudos de Usabilidade

\begin{tabular}{|c|c|c|c|c|c|c|}
\hline & $\begin{array}{l}\text { AVALIAÇÃO } \\
\text { DE PRODUTO } \\
\text { (SOMATIVO) }\end{array}$ & $\begin{array}{c}\text { DESENVOLVIMENTO } \\
\text { DE PRODUTO } \\
\text { (FORMATIVO) }\end{array}$ & $\begin{array}{l}\text { TESTES CLINICOS } \\
\text { EXPERIMENTAIS }\end{array}$ & $\begin{array}{c}\text { GERENCIAMENTO } \\
\text { DE RISCO }\end{array}$ & $\begin{array}{c}\text { GERENCIAMENTO } \\
\text { DE FALHAS }\end{array}$ & $\begin{array}{c}\text { EDUCAÇÃO, } \\
\text { CAPACITAÇÃO, } \\
\text { TREINAMENTO }\end{array}$ \\
\hline & $32,1 \%$ & $22,4 \%$ & $28,6 \%$ & $6,6 \%$ & $6,1 \%$ & $4,1 \%$ \\
\hline $\begin{array}{l}\text { TOTAL } \\
196\end{array}$ & 63 & 44 & 56 & 13 & 12 & 8 \\
\hline
\end{tabular}

Referências:

Desenvolvimento de produto (Formativo): [40], [155], [42], [131], [133], [111], [112], [46], [1], [47], [48], [142], [145], [49], [35], [50], [157], [158], [114], [116], [118], [58], [59], [60], [64], [67], [122], [146], [125], [147], [126], [127], [77], [79], [80], [87], [89], [92], [149], [103], [108], [152], [109].

Avaliação de produto (Somativo): [41], [154], [42], [132], [156], [45], [113], [134], [51], [115], [160], [52], [53], [117], [54], [55], [56], [57], [61], [119], [62], [63], [137], [65], [138], [68], [120], [69], [70], [123], [73], [74], [75], [76], [148], [78], [82], [83], [129], [84], [85], [86], [88], [90], [91], [94], [95], [96], [97], [130], [159], [150], [98], [99], [100], [151], [101], [102], [104], [105], [106], [107], [153].

Testes clínicos Experimentais: [40], [41], [155], [42], [156], [111], [46], [113], [1], [47], [48], [142], [145], [50], [157], [158], [51], [114], [160], [54], [55], [57], [59], [60], [61], [64], [67], [138], [122], [146], [123], [124], [73], [147], [126], [77], [78], [83], [129], [85], [87], [88], [89], [149], [159], [150], [98], [99], [101], [103], [105], [106], [107], [108], [152], [109].

Gerenciamento de risco: [154], [141], [144], [45], [136], [55], [66], [121], [69], [122], [72], [78], [80].

Gerenciamento de falhas: [110], [132], [44], [112], [119], [71], [76], [89], [97], [104], [140], [153].

Educação, Capacitação, Treinamento: [40], [41], [144], [43], [133], [134], [160]. 


\subsubsection{QUESTÃo 3: Quais a PRINCIPAIS TÉCNICAS de usabilidade que mais estão sendo empregadas?}

Para a Questão 3, nos resultados da Tabela 3 apresentamos um total de 196 artigos avaliados artigos, e percebemos então, que a Análise de Tarefas obteve o maior índice de 31,6\% (62 de 196), já para os que aplicaram a Simulação de Cenários ou Ambientes Clínicos Simulados, na avaliação dos DM foram cerca de 18,4\% (36 de 196). E que 12,8\% (25 de 196) dos artigos analisados aplicaram Questionários nas avaliações de Usabilidade, e os que aproveitaram das Entrevistas foram 8,2\% (16 de 196), diferente da Engenharia de Fatores Humanos que alcançou 7,7\% (15 de 196) dos artigos revisados avaliaram o DM utilizando-se desta técnica, para aplicar o conhecimento científico nas capacidades e limitações do usuário. Próximo a este, mas um número menor do que outros resultados: a técnica dos Grupos Focais 11 de 196 (5,6\%), da Análise Cognitiva 11 de 196 (5,6\%). Para as classificadas como Outros (somados os resultados das técnicas: Narração (Storytelling) e Taxonomia de Erro Humano) um número de 5,1\% (10 de 196), e juntas Heurísticas e Interação Homem-Máquina, foram 5 de 196 (2,6\%).

Tabela 3: Resultados da triagem: PRINCIPAIS TÉCNICAS de Usabilidade empregadas

\begin{tabular}{|c|c|c|c|c|c|c|c|c|c|c|}
\hline & $\begin{array}{l}\text { ANÁLISE } \\
\text { DE } \\
\text { TAREFAS }\end{array}$ & $\begin{array}{l}\text { SIMULAÇÃO } \\
\text { DE CENÁRIOS }\end{array}$ & QUESTIONÁRIOS & ENTREVISTAS & $\begin{array}{c}\text { ENGENHARIA } \\
\text { DE FATORES } \\
\text { HUMANOS }\end{array}$ & $\begin{array}{l}\text { GRUPOS } \\
\text { FOCAIS }\end{array}$ & $\begin{array}{c}\text { ANÁLISE } \\
\text { COGNITIVA }\end{array}$ & OUTROS I & HEURÍSTICA & $\begin{array}{c}\text { INTERAÇÃO } \\
\text { HOMEM- } \\
\text { MÁQUINA }\end{array}$ \\
\hline & $31,6 \%$ & $18,4 \%$ & $12,8 \%$ & $8,2 \%$ & $7,7 \%$ & $5,6 \%$ & $5,6 \%$ & $5,1 \%$ & $2,6 \%$ & $2,6 \%$ \\
\hline $\begin{array}{l}\text { TOTAL } \\
196\end{array}$ & 62 & 36 & 25 & 16 & 15 & 11 & 11 & 10 & 5 & 5 \\
\hline
\end{tabular}

Referências:

Análise de tarefas: [40], [41], [154], [155], [141], [110], [131], [156], [133], [112], [113], [48], [142], [145], [35], [157], [115], [52], [54], [55], [59], [119], [64], [66], [67], [68], [120], [143], [121], [122], [146], [123], [71], [73], [125], [74], [76], [148], [77], [78], [83], [129], [87], [88], [90], [91], [95], [149], [159], [150], [98], [99], [100], [151], [101], [102], [103], [104], [140], [152], [109], [153].

Simulação de cenários: [154], [42], [110], [144], [156], [133], [113], [47], [142], [51], [56], [57], [58], [64], [65], [67], [138], [120], [143], [69], [70], [122], [72], [74], [75], [78], [129], [88], [89], [92], [96], [99], [104], [106], [108], [152].

Questionários: [111], [134], [50], [51], [116], [117], [118], [58], [61], [124], [126], [127], [84], [85], [91], [93], [94], [96], [130], [150], [98], [100], [151], [107], [109].

Entrevistas: [41], [43], [160], [136], [118], [60], [67], [69], [122], [123], [79], [84], [87], [98], [100], [151].

Engenharia de Fatores Humanos: [141], [132], [156], [45], [135], [62], [137], [74], [76], [128], [86], [88], [89], [97], [139].

Grupos focais: [43], [46], [1], [145], [49], [114], [160], [136], [53], [118], [92].

Análise cognitiva: [141], [132], [63], [147], [75], [76], [128], [85], [91], [102], [140].

Outros: [41], [141], [44], [49], [51], [136], [61], [122], [130], [140].

Heurística: [132], [158], [122], [82], [91].

Interação Homem-Máquina: [141], [120], [143], [140], [109]. 


\subsubsection{QUESTÃo 4: Qual o PÚBLICO-ALVO dos estudos?}

Para a Questão 4, apresentamos os resultados de qual público alvo encontrados, e expostos na Tabela 4. Onde atingimos um saldo de 64,9\% (96 de 148) dos periódicos analisados que aplicaram seus estudos de Usabilidade para atender os Pacientes/Usuários Leigos, foram 7,4\% (11 de 148), dentre estes 60,8\% (90 de 96) receberam exclusivamente os Pacientes/Usuários Leigos (sem restrição) e 4,1\% (6 de 96) para Defientes/Idosos como público-alvo. E os que aplicaram Usabilidade na avaliação dos DM para os Médicos/Residentes foram cerca de $13,5 \%$ (20 de 148) para Técnicos/Auxiliares/Estudantes cerca de 8,8\% (13 de 148), e para os Enfermeiros 7,4\% (11 de 148). Estes números são muito maiores do que os estudos onde não foram definidos os usuários, os quais denominamos de Não Especificado 8 de 148 (5,4\%).

Tabela 4: Resultados da triagem: PÚBLICO ALVO dos estudos de Usabilidade

\begin{tabular}{lcccc}
\hline Pacientes / Usuários Leigos & Médicos Residentes & Técnicos Auxiliares Estudantes & $\begin{array}{c}\text { Enfermeiros } \\
\text { Não } \\
\text { especificado }\end{array}$ & $\begin{array}{c}\text { Total } \\
\text { parcial }\end{array}$ \\
\hline Sem restrições (90) & $60,8 \%$ & $13,5 \%$ & $8,8 \%$ & $7,4 \%$ \\
& & & 60 & $\mathbf{1 3}$ \\
Deficientes / Idosos (6) & $4,1 \%$ & $\mathbf{9 6}$ & $\mathbf{2 0}$ & $\mathbf{8}$ \\
\hline $\mathbf{1 4 8} \quad$ TOTAL & $\mathbf{6 4 , 9 \%}$ & & & $\mathbf{1 1}$ \\
\hline
\end{tabular}

Referências:

Pacientes / Usuários Leigos - Sem restrições: [41], [155], [42], [141], [131], [156], [43], [133], [111], [112], [45], [46], [113], [1], [48], [145], [49], [134], [157], [158], [51], [114], [115], [52], [136], [53], [116], [118], [54], [55], [56], [57], [59], [60], [62], [63], [64], [67], [121], [70], [146], [123], [125], [147], [75], [76], [126], [148], [127], [78], [79], [80], [81], [161], [83], [84], [85], [86], [87], [88], [89], [90], [91], [92], [93], [94], [95], [96], [97], [130], [159], [150], [98], [99], [100], [139], [151], [101], [102], [103], [104], [140], [105], [106], [107], [108], [152], [109], [153].

Pacientes / Usuários Leigos - Deficientes / Idosos: [40], [156], [158], [115], [53], [98].

Médicos Residentes: [110], [144], [44], [47], [142], [160], [117], [118], [56], [58], [119], [65], [138], [68], [120], [143], [123], [71], [74], [77].

Técnicos Auxiliares Estudantes: [154], [144], [132], [44], [1], [118], [58], [59], [61], [66], [71], [73], [79].

Enfermeiros: [41], [154], [44], [50], [51], [56], [122], [72], [124], [148], [129].

Não especificado: [132], [44], [112], [51], [135], [137], [69], [128]. 


\subsubsection{QUESTÃO 5: Quais as ESPECIALIDADES encontradas nos estudos?}

Das especialidades médicas encontradas nos estudos, os números analisados onde os pesquisadores aplicaram a Engenharia de Usabilidade estão na Tabela 5 (próxima página). Desta forma, na ciência da Gastroenterologia foram 9 de 54 (16,7\%), para Imagens/Medicina Nuclear 7 de 54 (13\%), Anestesiologia localizados 7,4\% (4 de 54), Fisioterapia/Reabilitação 4 de 54 (7,4\%), na área de Respiratória/Pulmonar 7,4\% (4 de 54). Para o Diagnóstico das enfermidades, na Endocrinologia, em Neurologia, e Urologia foram achados igualmente 5,6\% (3 de 54). De Cardiologia, Nefrologia, Oftalmologia, Oncologia e Ortopedia/Geriatria/Reumatologia obtive-se igualmente 3,7\% (2 de 54). E um número menor do que todas as outras, com apenas 1,9\% (1 de 54) igualmente a Dermatologia, Hematologia, Odontologia e Veterinária, aplicaram a Engenharia de Usabilidade em suas especificidades.

Tabela 5: Resultados da triagem: ESPECIALIDADES encontradas nos estudos de Usabilidade

\begin{tabular}{|c|c|c|c|c|c|c|c|c|c|c|c|c|c|c|c|c|c|c|}
\hline & GASTRO & IMAGENS & $\begin{array}{l}\text { ANES } \\
\text { TESIO }\end{array}$ & FISIO & $\begin{array}{c}\text { RESPIRA } \\
\text { TORIA }\end{array}$ & $\begin{array}{l}\text { DIAGNós } \\
\text { TICO }\end{array}$ & $\begin{array}{l}\text { ENDO } \\
\text { CRINO }\end{array}$ & NEURO & UROLO & CARDIO & NEFRO & OFTAL & onco & ORTO & DERMA & HEMATO & ODONTO & VETE \\
\hline & $16,7 \%$ & $13,0 \%$ & $7,4 \%$ & $7,4 \%$ & $7,4 \%$ & $5,6 \%$ & $5,6 \%$ & $5,6 \%$ & $5,6 \%$ & $3,7 \%$ & $3,7 \%$ & $3,7 \%$ & $3,7 \%$ & $3,7 \%$ & $1,9 \%$ & $1,9 \%$ & $1,9 \%$ & $1,9 \%$ \\
\hline $\begin{array}{l}\text { TOTAL } \\
54\end{array}$ & 9 & 7 & 4 & 4 & 4 & 3 & 3 & 3 & 3 & 2 & 2 & 2 & 2 & 2 & 1 & 1 & 1 & 1 \\
\hline
\end{tabular}

Referências:

Gastroenterologia: [155], [162], [46], [49], [68], [71], [97], [104], [105].

Imagens/Medicina Nuclear: [138], [73], [79], [99], [101], [152].

Anestesiologia: [111], [55], [56], [106].

Fisioterapia Reabilitação: [40], [52], [95], [149].

Respiratória/Pulmonar: [45], [84], [150], [107].

Diagnóstico: [154], [42].

Endocrinologia: [139], [96], [159].

Neurologia: [62], [146], [90].

Urologia: [47], [65], [85].

Cardiologia: [100], [78].

Nefrologia: [157], [146].

Oftalmologia: [145], [118].

Oncologia: [41], [121].

Ortopedia/Geriatria/Reumatologia: [156], [1].

Dermatologia: [43].

Hematologia: [134].

Odontologia: [119].

Veterinária: [113]. 


\subsubsection{QUESTÃO 6: Quais os LOCAIS DE APLICAÇÃO dos estudos?}

Para os resultados que responderam à Questão 6 (Tabela 6), pode-se notar que o local chamado EAS (Estabelecimentos de Assistência a Saúde), foi assim denominado para os estudos onde não foi definido o local exato da pesquisa, os quais foram localizados $48 \%$ (36 de 75). Já para o local denominado Homecare, no tratamento dos usuários em casa, obtevese $25 \%$ (19 de 75). No local cognominado Cirurgia/Cuidados Intensivos, nos resultados foram encontrados 8\% (6 de 75), Na Emergência/Pronto Socorro onde se concentraram estas áreas comuns, recebeu o número de 7\% (5 de 75). Para o que denominamos de Telemedicina, ou atendimento à distância, foram achados 5\% (4 de 75). E no Laboratório de Análises Clínicas foram descobertos 4\% (3 de 75). Para os estudos aplicados no Ambulatório e no Laboratório de Eletrônica/Automação igualmente apenas 1\% (1 de 75), que aplicaram estudos de Engenharia de Usabilidade.

Tabela 6: Resultados da triagem: LOCAIS DE APLICAÇÃO dos estudos de Usabilidade

\begin{tabular}{|c|c|c|c|c|c|c|c|c|}
\hline & $\begin{array}{c}\text { EAS } \\
\text { (Estabelecimento } \\
\text { Assistencial de } \\
\text { Saúde) } \\
\end{array}$ & HOMECARE & $\begin{array}{c}\text { CIRURGIA / } \\
\text { CUIDADOS INTENSIVOS / } \\
\text { UNIDADE TERAPIA } \\
\text { INTENSIVA(UTI) }\end{array}$ & $\begin{array}{c}\text { EMERGÊNCIA/ } \\
\text { PRONTO } \\
\text { SOCORRO }\end{array}$ & TELEMEDICINA & $\begin{array}{l}\text { LABORATÓRIO } \\
\text { DE ANÁLISES } \\
\text { CLÍNICAS }\end{array}$ & AMBULATÓRIO & $\begin{array}{l}\text { LABORATÓRIO } \\
\text { ELETRÔNICA } \\
\text { AUTOMAÇÃOO }\end{array}$ \\
\hline & $48 \%$ & $25 \%$ & $8 \%$ & $7 \%$ & $5 \%$ & $4 \%$ & $1 \%$ & $1 \%$ \\
\hline TOTAL & 36 & 19 & 6 & 5 & 4 & 3 & 1 & 1 \\
\hline
\end{tabular}

Referências:

EAS (Estabelecimento Assistencial de Saúde): [110], [131], [144], [132], [112], [49], [50], [51], [114], [160], [52], [135], [136], [118], [61], [137], [120], [69], [163], [123], [124], [147], [75], [76], [80], [128], [129], [87], [91], [92], [93], [130], [151], [140], [153].

Homecare: [42], [141], [156], [133], [115], [53], [60], [64], [67], [70], [126], [81], [83], [86], [88], [89], [98], [102], [152].

Cirurgia/Cuidados intensivos: [57], [58], [125], [94], [103], [108].

Emergência/Pronto Socorro: [110], [142], [54], [62], [143].

Telemedicina: [43], [116], [74], [148].

Laboratório de Análises Clínicas: [154], [42], [66].

Ambulatório: [41].

Laboratório de Eletrônica/Automação: [82]. 


\section{DISCUSSÃO}

Neste capítulo, serão expostas as discussões sobre os resultados investigados a respeito do uso da Usabilidade nos Dispositivos Médicos, considerando os itens de cada tema de mais relevância, dentro da RSL.

\subsection{QUESTÃO 1: QUAIS AS APLICAÇÕES DOS ESTUDOS?}

Importante notar que os resultados do componente Apenas Hardware, onde obtivemos 49\% (71 de 144) dos periódicos analisados, que aplicaram a Usabilidade apenas para o Hardware dos Dispositivos Médicos, confirmam serem imperativas as análises dos equipamentos médicos, a fim de obter requisitos de eficácia, segurança e confiabilidade. [6].

A maioria dos pesquisadores é unânime, chegando a ser redundante, em confirmar que a crescente complexidade da tecnologia médica torna a Usabilidade um importante critério de seleção para um novo equipamento (Hardware) por um EAS. No entanto, recomenda que para isso, requer antes uma compreensão do que seja Usabilidade, para poder escolher adequados métodos de avaliação [152]. Também, indicam o envolvimento do usuário, através da incorporação de Métodos de Engenharia dos Fatores Humanos (MDDD), no âmbito dos projetos e desenvolvimento do DM [159]. E resumem os cuidados com o DM, que sejam eficazes, eficientes, e que obtenham satisfação dos usuários [175].

Para os resultados Apenas Software os quais obtivemos 14,5\% (21 de 144) dos títulos analisados, que aplicaram a Usabilidade apenas para o Software dos DM, segundo maior no interesse, nota-se que no desenvolvimento de DM, existe uma elevada pressão impostas pelo mercado para lançar novos produtos, e com o poder computacional aumentando, permite-se aos projetistas criarem cada vez mais funcionalidades aos softwares, levando também a dificuldades em se verificar erros de design. [164]

No artigo [88], foi apresentada a experiência de um projeto da aplicação da norma europeia EN IEC 62304:2006, que define os requisitos do ciclo de vida, para o desenvolvimento e manutenção de software de DMs [165], com o objetivo de avaliar o software de uma unidade de radioterapia, para a garantia de sua qualidade, e adquirir habilidades na aplicação desta norma em um ambiente hospitalar. Foram avaliados os 
requisitos mínimos para cada fase do ciclo de vida do software, definindo as atividades e tarefas a serem executadas e documentação e testes, de acordo com sua criticidade. Como conclusão, a aplicação da norma EN IEC 62304:2006 foi demorada, e o tempo de aprendizagem tinha que ser superado durante as primeiras iterações dos processos, porém muitas das descrições utilizadas nos processos e todas as ferramentas de software puderam ser reaproveitadas em projetos paralelos. E que, este é um desenvolvimento compatível com os padrões de pequenas e médias empresas de softwares médicos, realizado por pequena equipe, e recursos limitados em um ambiente clínico, e relevante para reforçar os requisitos legais atuais, para os fabricantes europeus. [88]

O parâmetro Apenas Processos alcançou somente 6,9\% (10 de 144) dos periódicos considerados, que aplicaram a Usabilidade apenas para os Processos dos DM. E segundo [10], através de seus estudos, revelaram que os principais benefícios do envolvimento dos usuários dos DM, foram: o maior acesso às necessidades do usuário; experiências e idéias, gerando melhorias: nos projetos DM; nas interfaces do usuário; aumento na funcionalidade; facilidade de utilização; e na qualidade dos dispositivos. E para [12], que utilizou na sua pesquisa métodos de Engenharia de Fatores Humanos (HFE), para investigar a relação entre a frequência de comunicação de NFF (No Fault Found), e a Usabilidade dos dispositivos médicos. Estes DMs eram enviados para reparos à Engenharia Clínica, onde eram identificados estarem em perfeito estado de funcionamento. A análise dos materiais, dos DMs, e dos dados de manutenção, foram realizadas para identificar os dispositivos que tinham uma maior frequência de comunicação de NFF. Foram aplicadas entrevistas e avaliações heurísticas, a fim de identificar potenciais problemas de usabilidade, para validar as falhas ocultas de design de Usabilidade relacionadas com a comunicação de NFF. Como resultado da análise dos dados da manutenção, identificaram seis dispositivos com uma frequência de comunicação de NFF alta, e revelados problemas de usabilidade que causavam uma parcela significativa relatórios de NFF. Outros fatores suspeitos de contribuir para o aumento destes relatos, incluíam as questões relacionadas aos acessórios, falhas intermitentes e problemas ambientais. Nos Testes de Usabilidade realizados em três dos dispositivos, foram reveladas 23 falhas de projetos ocultos de Usabilidade, demonstrando que as falhas de design ocultos de Usabilidade, manifestaram-se com um aumento dos NFF 
destes equipamentos, e que os dispositivos que continham falhas de design, poderiam ser identificados através da análise dos dados de manutenção dos DMs. [12].

Para a combinação dos resultados Software e Processos, obteve-se um número muito menor do que os de avaliação de duplo domínio, de 2,1\% (3 de 144). Embora não seja um número considerável, mas avaliando-se o periódico de [8], o qual expõe que devido à crescente automação, e a complexidade nas técnicas e nos componentes dos DMs, e com as novas opções terapêuticas e de diagnóstico existentes terem que ser imperativamente eficazes e eficientes, frequentemente as interfaces dos usuários, baseadas em computador, podem levar à um risco potencial induzido pelo ser humano. Onde o pesquisador sugere, que a análise deste risco humano, seja realizada de forma sistemática e precoce, com uma avaliação através de técnicas de usabilidade, permitindo que os fabricantes de DM identifiquem e controlem os riscos dentro da interação homem-máquina, de forma mais eficiente. No Departamento de Engenharia Médica no Instituto Helmholtz de Engenharia Biomédica da RWTH Aachen University, na Alemanha, uma metodologia formal-analítica e uma ferramenta de software, foram desenvolvidas para a análise do risco humano e avaliação de Usabilidade baseados em modelos. Com base em uma abordagem concomitante, das sequências do processo interativo e do usuário, e de seus potenciais impactos sobre o processo geral, são identificados os riscos relacionados com a utilização do DM [8].

A maior superposição Hardware-Software é justificável uma vez que a avaliação conjunta componentes de hardware e software na análise do DM foi descrita como método de encontrar violações relacionadas à integração do sistema durante todo o seu desenvolvimento, podendo ajudar a identificar pontos fortes e oportunidades de melhorias dos DM, mitigando riscos. [4]. Em uma das investigações, o objetivo foi desenvolver e implantar um sistema de apoio para a vida de idosos, em um ambiente de enfermagem operado em casa, e avaliar o seu desempenho e Usabilidade em condições reais, e enfatizado a importância de implementações em ambientes do mundo real, em oposição aos protótipos com testes em laboratórios. A pesquisa foi conduzida em Cingapura, e com a participação de oito pacientes com demência e dois cuidadores, aplicando uma solução de apoio que consistia em um conjunto de sensores e dispositivos controlados por uma plataforma de software, e implantados no lar dos idosos, precedido por um período de pré-implantação, afim de organizar sessões de observações (análise de tarefas) com os pacientes enfermos, e 
a técnica de grupos focais para os cuidadores. Um sistema de avaliação de desempenho foi realizado durante o período de implantação, com a ajuda de profissionais de saúde. Como resultados, os pacientes em observação, surgiram requisitos e problemas mais concretos que deveriam ser tratados, e que não poderiam ser identificados em ensaios de laboratório. Questões que foram previstas durante a fase de projeto, nem durante os testes de laboratório, foram à tona durante a implantação, afetando a eficácia da solução proposta. Em decorrência da avaliação do desempenho do sistema, revelou-se uma evolução da precisão do sistema ao longo das fases de implantação, enquanto que a análise dos dados demonstrou a capacidade de fornecer e detectar de forma precoce a degradação dos pacientes afetadas com demência, e que perdem progressivamente a sua autonomia. [25]

Observa-se que para Hardware e Processos, com apenas 4,1\% (6 de 144), avaliar o DM de forma concomitante, tem como objetivo simular a interação entre o ambiente e o sistema, conforme [164], podemos recolher dados reais, por exemplo, do hardware de um sensor de Oxímetro de Pulso em tempo real e depois colocá-los em um arquivo que pode ser usado durante a fase de simulação, podendo adaptar a função de ler os dados a partir do arquivo armazenado no PC, em vez de ler esta informação diretamente no sensor. Este tipo de estratégia é aplicável a uma grande variedade de DM, porque a maior parte deles tem uma fase de aquisição de dados, outra de aplicação de um algoritmo, seguido pela produção de um resultado. E no trabalho [173], foi avaliado um Sistema de Controle de Glicose (SGC), que é um dispositivo assistido por computador, e orientado para uso na enfermagem, para o controle glicêmico, combinado com uma bomba de infusão. E com o objetivo de investigar o desempenho do SGC em pacientes, foram realizados na Áustria e Zurique, na Suíça, avaliação a fim de verificar a eficácia através da percentagem de tempo de uso, a média de glicose no sangue, e intervalo de amostragem, e a segurança avaliada pelo número de episódios de hipoglicemia. A Usabilidade foi analisada através de questionários padronizados, aplicados ao pessoal envolvido de enfermagem, e em 40 pacientes. E foi concluído que o equipamento SGC, é um método seguro e eficiente para controlar a glicemia em pacientes.

O único trabalho que aborda Usabilidade nos três domínios, Hardware-SoftwareProcessos, descreve estratégias para apoiar o uso de handheld PC (PDA - Personal Digital Assistant) na prática clínica. O estudo utilizou metodologias de grupos focais e entrevistas. 
Seus resultados identificaram respostas ligadas às necessidades do usuário em relação a Usabilidade, obtendo retornos sobre as estratégias de apoio ao PDA, por exemplo, como facilitar o usuário médico aprimorando o dispositivo; as preocupações com a segurança do DM, a necessidade do fornecimento de treinamento e suporte ao usuário [60].

\subsubsection{Resultados da Análise Estatística}

O método estatístico ANOVA, para examinarmos quais dos domínios Hardware (HW), Software (SW) ou Processos (PR), e suas superposições SW + PR, HW+SW, HW+PR e $\mathbf{H W}+\mathbf{S W}+\mathbf{P R}$, possuem maior antiguidade entre os artigos, dentro da faixa de tempo pesquisada (10 anos), obtiveram os seguintes resultados, expostos abaixo na Figura 2, através do Diagrama de Venn (i.e., dos conjuntos), que organiza a relação entre os dados colhidos.

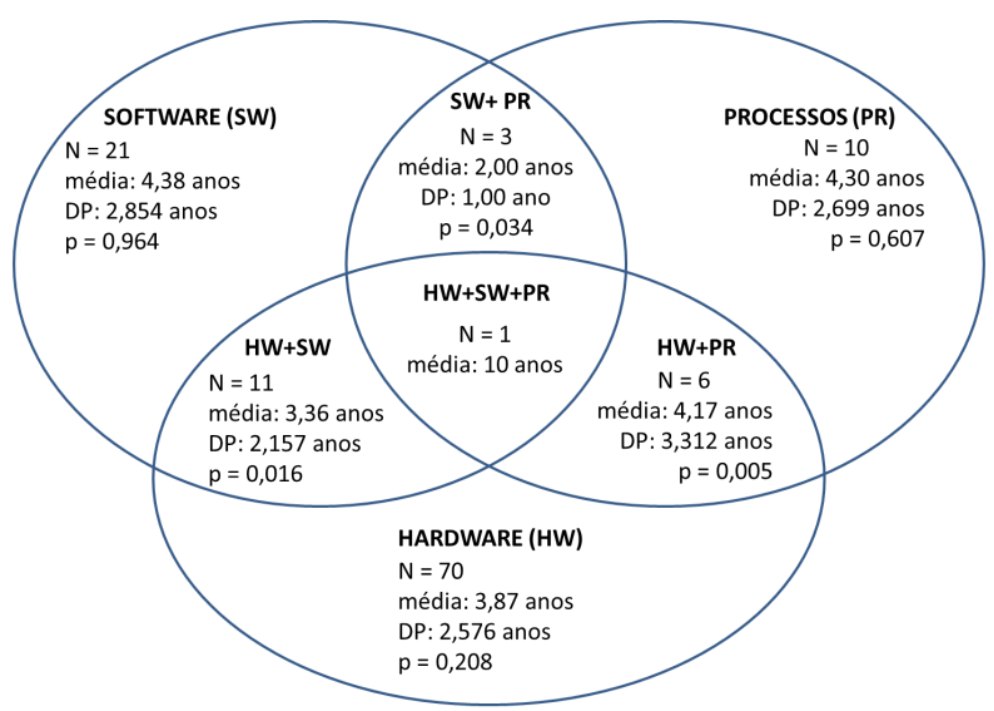

Figura 2: Resultados estatísticos da antiguidade dos artigos sobre Hardware, Software e Processos, de 122 Artigos - Últimos 10 Anos: ANOVA, $p=0,220$; Chi-quadrado: $p<0,001$.

A diferença entre os perfis de tempo de publicação não é significativa no geral $(\mathrm{p}=$ 0,220), no entanto é significativa nas associações $\mathbf{H W + P R}, \mathbf{H W + S W}$ e $\mathbf{S W}+\mathbf{P R}$. E em relação as frequências de casos em cada categoria, ou seja, a quantidade das publicações e não o tempo de publicação em cada categoria ou intersecção de categorias, foi utilizado o teste chi-quadrado, distribuição utilizada para avaliar quantitativamente a relação entre os 
resultados e a sua distribuição esperada. Isto é, ele nos diz com quanta certeza os valores observados podem ser aceitos como regidos pela teoria em questão.

Como resultado $\mathrm{p}<0,001$, ou seja, menos de $0,1 \%$ de chance dessa quantidade de publicações ser fruto do simples acaso. Podendo-se então afirmar, que nos últimos 10 anos, houve um interesse maior na publicação de Usabilidade associada ao Hardware de Dispositivos Médicos, do que aos Softwares ou Processos, sem que algum assunto tenha de fato começado a ser abordado antes dos outros no período observado. E também, pelas razões já expostas na introdução desta pesquisa, neste intervalo de 10 anos, existe ainda uma distância significativa para a realidade brasileira, devido ao hiato que temos pela falta de exigência compulsória para as normas de Usabilidade em DM, mas não é esta a realidade global. E cabe ressaltar, que nem autores brasileiros em publicações internacionais foram registrados na lista obtida.

\subsection{QUESTÃO 2: QUAIS OS OBJETIVOS DOS ESTUDOS?}

Comparando os valores de duas características semelhantes, o Gerenciamento de Risco e o Gerenciamento de Falhas, compreende-se o resultado de $1 \%$ maior para o Gerenciamento de Risco, mostrando que embora pequena, há uma maior preocupação com esta avaliação, controle e monitoração de risco, quando esta aplicação pode afetar a segurança, a saúde humana, ou a integridade profissional, de acordo com a Anvisa. Nas pesquisas que aplicaram os Testes de Usabilidade em um novo dispositivo de caneta de auto-injeção pelo paciente de medicamentos subcutânea (IFU) [166] [148], os estudos foram realizados com uma ampla população de usuários, cujos objetivos foi confirmar que a caneta pode ser usada sem os padrões de erros de uso que conduzem a situações perigosas recorrentes, e avaliar a compreensão das instruções de uso da caneta, e para determinar se o treinamento seria necessário. Num total de 36 participantes após cada um ler as instruções, preparar o dispositivo, e realizar duas injeções simuladas em uma almofada de injeção, não foram registados quaisquer erros de uso, quase-acidentes ou desvios do procedimento. A taxa de sucesso global foi de $94 \%$ para a primeirtentativa, e de $100 \%$ para a segunda. Onde $92 \%$ dos participantes relataram que se sentiam confiantes usando o dispositivo, $100 \%$ acharam o IFU útil, e 75\% acharam o dispositivo positivamente confortável de usar. Concluiu-se que a pena injetora poderia ser segura e eficiente, usada por todos os grupos de usuários, sem nenhum 
treinamento, e o dispositivo na sua forma atual, é bem adequado para uso em uma grande variedade de aplicação.

Para a dupla: Desenvolvimento de produto (Formativo) e Avaliação de produto (Somativo) alertamos que na realidade, as avaliações dos DMs estão sendo aplicadas de forma inadequada, onde $32,1 \%$ dos estudos, o produto está sendo avaliado já pronto (Somativo), contra $22,4 \%$ na fase de desenvolvimento do produto (Formativo), que conforme [4] sugere, que esta avaliação aconteça de forma imperativa na fase de desenvolvimento do DM (Formativo). E a norma ABNT NBR IEC 62366:2016 - Produtos para a saúde - Aplicação da Engenharia de Usabilidade a Produtos para a Saúde, recomenda que: “...que a ENGENHARIA DE USABILIDADE, incluindo a VALIDAÇÃO DE USABILIDADE, comece desde o início e continue através do ciclo de vida de desenvolvimento do PRODUTO PARA A SAÚDE" [23] (grifos nossos). E em nossas pesquisas, observamos que o desenvolvimento de novos produtos, juntamente com à inovação, é apontado como uma ferramenta essencial para o crescimento das empresas e sua diferenciação dos concorrentes. Com este pensamento a pesquisadora Isa et al [32], faz uma revisão de literatura, selecionando Modelos existentes, aplicados ao Processo de Desenvolvimento do Produto (PDP) e também aos Dispositivos Médicos (DM). Em geral, os Modelos facilitam a compreensão e a comunicação, melhorando o PDP, o gerenciamento, a automação; fazendo previsões, testando hipóteses. A Modelagem de Processos, refere-se à atividade de representar processos e, nesta pesquisa de Isa et al, os Modelos sobre o PDP, foram revistos a partir de 33 publicações analisadas, especialmente para dispositivos médicos, chegando a conclusão que até o momento, não existe um Modelo abrangente na literatura para esta finalidade. Porém, estes Modelos de Processos contribuem para uma boa tomada de decisão das empresas, os produtos chegam ao mercado mais rapidamente, dando assim uma vantagem competitiva e melhor retorno financeiro. Desde que o Modelo de Usabilidade escolhido seja o mais adequado ao PDP, com as informações que o Modelo deve conter, identificando o que pode ser melhorado, ou mesmo como as informações devem ser representadas. Os sujeitos envolvidos no design do DM ao saber dos múltiplos Modelos disponíveis, devem escolher o caminho mais adequado para que possa ser adaptado às suas necessidades e realidades. Segundo Isa et al [32], com a sua revisão, destacou três Modelos, que podem ser aplicados do PDP dos DM: Business Process Modeling Notation - BPMN: definida como linguagem gráfica adequada para comunicar os processos de negócios para 
grandes públicos, e projetada para coordenar a sequência de processos e mensagens que circulam entre processos de diferentes participantes); Flowchart: o conhecido Fluxogramas, é uma representação esquemática que apresenta solução passo-a-passo para um determinado problema, onde as operações do Processo são representadas por diferentes caixas que estão ligados por setas, que simbolizam o fluxo do processo, eficiente e eficaz para organizar e visualizar Processos, especialmente envolvendo lógica; e Unified Modeling Language $U M L$ : linguagem de modelagem visual rica e expressiva, que pode acomodar os pontos de vista dos vários interventores, evitando a necessidade de recorrer a notações múltiplas, a fim de representar os processos, e tambem pode ser utilizada para especificar, visualizar, construir documentos de um Sistema de Software. [32]

Os valores dos Testes Clínicos/Experimentais, apresentam um resultado expressivo de 28,6\%, confirmando a relevância dos testes clínicos experimentais aplicados aos DMs preconizados por [4]. E para o desenvolvimento de uma ferramenta para o monitoramento da dor, com pacientes submetidos à colonoscopia, para a detecção e prevenção do câncer colo-retal, Niv [18], apresentou as experiências de pacientes que passaram por procedimentos endoscópicos, onde não é raro dor durante o exame. Propuseram um estudo de quatro estágios para o desenvolvimento de uma ferramenta dedicada ao monitoramento da dor durante a colonoscopia, da seguinte forma: (1) a comparação das respostas dos questionários elaborados para os pacientes, para a enfermeira, e para o endoscopista sobre a dor do paciente, bem como detalhes técnicos do procedimento, usando a nova ferramenta denominada de PAINAD, durante a colonoscopia; (2) observações da correlação entre as expressões faciais dos pacientes e outros parâmetros; (3) o desenvolvimento de um dispositivo para a monitorização contínua da expressão facial do paciente durante o procedimento; (4) avaliação da Usabilidade de tais ferramentas e sua contribuição para os procedimentos de colonoscopia. Onde os pesquisadores concluíram que a intervenção precoce pela equipe que realiza o procedimento, em relação as recomendações das reações codificadas do paciente, podem impedir eventos adversos durante o procedimento. [18]

Apesar da importância da Educação/Capacitação/Treinamento aplicados a Usabilidade dos DM, foi recomendado por [36] o treinamento do usuário, o impacto mais imediato para obter o uso seguro e eficaz dos DMs, e também sugerida pela norma que: “[...] o treinamento em um PRODUTO PARA A SAÚDE específico, pode ser utilizado para 
fornecer conhecimentos e habilidades requeridas para o uso seguro e efetivo do PRODUTO PARA A SAÚDE...” [23], onde obtivemos unicamente 4,1\% dos periódicos, que praticaram a Capacitação/Treinamento durante os testes dos DM. Porém, Lange et al, que praticou esta recomendação, apresentou resultados sobre a questões do treinamento do usuário antes do uso do DM. Em relação a confiança e o conforto na utilização do dispositivo, em um total de 43 participantes que receberam treinamento para o uso de injeções simuladas, todos os participantes foram capazes de usar com sucesso o dispositivo, com um grau de confiança de $98 \%$. [16]

\subsection{QUESTÃO 3: QUAIS AS PRINCIPAIS TÉCNICAS EMPREGADAS?}

Os parâmetros mais expressivos das técnicas que estão sendo utilizadas para avaliação dos DM, foram as Análises de Tarefas (31,6\%), prática que faz parte da primeira fase de avaliação da metodologia Combined Cognitive and Physical Evaluation (CCPE), condensada por pesquisadores [185], que avaliaram os métodos de avaliação comumente utilizados para avaliação de Usabilidade, muitas vezes se concentram em ergonomia cognitiva (avaliar carga de trabalho mental ou Usabilidade) ou a Ergonomia Física (carga de trabalho físico ou postura corporal), e propôs uma metodologia analítica conjunta condensada através de uma revisão sistemática, a fim de avaliar potenciais deficiências na interação entre o homem-máquina; tais como carga alta de trabalho físico e mental, erros de uso, problemas de usabilidade, e erros físicos ergonômicos, no homem, com o objetivo de alcançar uma abordagem de avaliação mais holística, e fazer a avaliação mais eficaz do que usar métodos de avaliação separados. A metodologia é baseada na Tarefa, o que torna possível a utilização de ambas as avaliações com foco no projeto e no desenvolvimento do DM, estabelecendo uma combinação de técnicas para a análise do DM. A Análise de Tarefas avalia e julga o DM, através das potenciais deficiências das tarefas, representadas por uma seqüência de atividades para alcançar um fim específico, executadas com a interação homem-máquina, para servir como base para um diagnóstico geral, fazendo uma analise crítica de onde poderá ser otimizado. A descrição desse sistema de julgamento consiste em quatro atividades combinadas: avaliar o Perfil do Usuário; Análise de Tarefas; Descrição do Contexto; e Descrição da Interação. 
Nos resultados da Simulação de Cenários foram coletados importantes $18,4 \%$. Comprovando, que para conduzir avaliações de Usabilidade com usuários, os investigadores estão cada vez mais usando simulação médica para padronizar cenários clínicos, simulando cenários específicos, e coletando padrões de Usabilidade, quando estas tarefas são difíceis, se não impossíveis de realizar nos vários grupos de pesquisas, que criam Laboratórios de Usabilidade. Mais de 130 instituições de cuidados da saúde dos EUA, desenvolveram centros de simulação médica, para treinar e avaliar professionais de saúde. Alguns fabricantes de DM já usam centros de simulação, como parte de seus processos de desenvolvimento de produtos, testes de fatores humanos, e a interação com outros centros de simulação médica, contribuindo para o desenvolvimento de novos produtos, treinamento do usuário final, e evolução dos DMs, e para estas instalações dedicadas e pessoal especializado, requerem investimentos em recursos para avaliação da Usabilidade. [89]

Examinando-se o relacionamento entre as práticas dos Questionários e das Entrevistas, na avaliação de Usabilidade, respectivamente obtivemos os resultados de 12,8\% e 8,2\%, confirmando-se os maiores números aos Questionários, já que são mais rápidos de serem implementados, e não necessitarem de validação [167], e são respondidas pelos usuários sem a intervenção de um interlocutor. E aplicada pelos pesquisadores, Park et al [123], que desenvolveram e avaliaram um aplicativo para telefone celular, plataforma Android, afim de apoiar a gestão eficaz da glicose no sangue para pacientes com diabetes, através da comunicação via Bluetooth comunicando-se com um glicosímetro, para troca e armazenamento de informações. A aplicação desenvolvida foi avaliada por cinco profissionais de saúde e 87 usuários, por meio de um Questionário, compreendendo as seguintes variáveis: intenção de uso, a expectativa de esforço, influência social, condição facilitada, percepção de risco, e voluntariedade. Como consequência da avaliação de Usabilidade, confirmou-se que a aplicação desenvolvida, é útil para auto-monitorização da glicose no sangue por pacientes diabéticos, e que também os profissionais de saúde, declararam que a aplicação é benéfica para observar as tendências de mudanças da glicose no sangue através da função automática que grava os níveis de glicose medidos, e a função que verifica os registos acumulados. [123] 


\subsection{QUESTÃO 4: QUAL O PÚBLICO-ALVO?}

O item esperado de maior índice, foram para os estudos que focaram os Pacientes/Usuários Leigos como público-alvo das suas pesquisas, com 64,9\% (96 de 148), atendendo completamente aos pesquisadores: [168], [25], [6], [169], [5], [26], [170], [22], [4], [37], dentre muitos outros, que indicam a participação efetiva dos usuários no desenvolvimento do DM. E para o pesquisador Wee [20], com a preocupação de desenvolver soluções para os usuários no Sistema de Saúde da Malásia, que possui muitas das informações médicas, ainda baseados em papel, propôs um protótipo de aplicativo para celular, com o objetivo de fornecer registros pessoais de saúde dos pacientes. Embora na região, existam vários sistemas de informação sanitária utilizados dentro de alguns hospitais, nenhum destes sistemas de informação de saúde lidam com registros individuais. E os dados de saúde que existem, estão concentrados em clínicas privadas ou hospitais públicos, onde os indivíduos são incapazes de acessá-los. Segundo o pesquisador, sem um registro completo, agentes de saúde são impossibilitados de compreender a imagem da saúde do indivíduo como um todo, o que os levam a erros médicos, interações medicamentosas e exames desnecessários. E ainda existe a dificuldades das muitas áreas rurais que não possuem acesso à Internet. Para isso, propôs uma solução por meio de um telefone celular, dispositivo comum em todo o mundo, desenvolvendo o aplicativo Portable Personal Health Record (PPHR), projetado para gerenciar registros pessoais de saúde, já incorporadas com melhorias de acessibilidade, disponibilidade e Usabilidade, confirmando sua utilidade e encontrando uma preocupação, até então desconhecida, dos indivíduos na Malásia com relação aos seus próprios dados de saúde [20]. Pode-se observar, que o Sistema de Saúde da Malásia não é muito diferente do Sistema de Saúde do Brasil.

E apresentamos para os Médicos/Residentes foram 13,5\% (20 de 148), Técnicos/Auxiliares/Estudantes 8,8\% (13 de 148), Enfermeiros 7,4\% (11 de 148), e para os Não Especificado 8 de 148 (5,4\%).

\subsection{QUESTÃO 5: QUAIS AS ESPECIALIDADES ENCONTRADAS?}

Das especialidades médicas que retornaram maiores índices foram: primeiro a Gastroenterologia $16,7 \%$ (9 de 54). Onde nos chama atenção que a maioria das pesquisas, 
[7], [23], [31], [84], aplicaram Testes de Usabilidade descrevendo redesign ou protótipos de equipamentos para diagnóstico, que conduzem a detecção de câncer, exames de colonoscopia, endoscopia, ou instrumentos como o laparoscópico, demonstrando a inquietação com equipamentos extremamente delicados e de grande risco a saúde humana.

Para as Imagens/Medicina Nuclear 13\% (7 de 54), estes números ratificam o interesse dos EAS nesta especialidade, em função da revolução que o processamento de imagens digitais tem causado no meio médico, das imagens produzidas e manipuladas, a possibilidade de adquirir dados, executar operações matemáticas para produzí-las, enfatizando detalhes, armazenando e resgatando imagens de forma remota, disponibilizando toda a informação de diagnóstico que se necessita, destacado por [171]. E como a indústria da saúde é dependente do fornecimento de dispositivos médicos bem projetados, e para alcançar este objetivo Martin, recomenda que o design do DM, seja centrado no usuário, e que comece cedo e de forma continuada ao longo do seu desenvolvimento. Este é um desafio, em especial para empresas pequenas que podem não ter a experiência, ou os conhecimentos necessários para tais ações. Preocupação dos estudos de Martin, [127], com o objetivo de realizar uma rigorosa investigação focada nas exigências dos usuários, para serem aplicadas em um novo dispositivo de Imaginologia Médica. Foram aplicadas entrevistas abertas, conduzidas aos usuários potenciais, com o objetivo de investigar a necessidade clínica deste DM, e os potenciais benefícios para pacientes e usuários clínicos. Como resultado, o estudo identificou uma série de novas necessidades, e sugeriram que o conceito do dispositivo fosse alterado, já que foram também identificados fatores que atuaram como barreiras à adoção segura e eficaz do DM. E que com essas sugestões atendidas, o fabricante poderia obter um produto de melhor qualidade, reduzindo o tempo de mercado, e economizando no custo de produção.

As demais especialidades, foram localizados Anestesiologia 7,4\% (4 de 54), Fisioterapia/Reabilitação 4 de 54 (7,4\%), na área de Respiratória/Pulmonar 7,4\% (4 de 54). Para o Diagnóstico das enfermidades, na Endocrinologia, em Neurologia, e Urologia igualmente 5,6\% (3 de 54). De Cardiologia, Nefrologia, Oftalmologia, Oncologia e Ortopedia/Geriatria/Reumatologia igualmente 3,7\% (2 de 54). E finalizando com 1,9\% (1 de 54) a Dermatologia, Hematologia, Odontologia e Veterinária, aplicaram a Engenharia de Usabilidade em suas especificidades. 


\subsection{QUESTÃO 6: QUAIS OS LOCAIS DE APLICAÇÃO DOS ESTUDOS?}

Dentre os três primeiros classificados, o local de aplicação chamado EAS

(Estabelecimentos de Assistência a Saúde), justificam os itens identificados de 44\% (36 de 75), devido a forma genérica como muitos artigos avaliaram um determinado DM, sem identificar o local de sua especialidade.

Porém, para o Homecare, estudos aplicados no tratamento dos usuários em casa, expressivos 23\% (19 de 75), foram encontrados, e que para [110], com os recentes avanços no âmbito de dispositivos portáteis, se tornou extremamente atrativo surgirem ferramentas para o campo da Telemedicina Móvel, devido à variedade de aplicações médicas que podem servir como ferramenta de diagnóstico, obtendo assim, grande riqueza de dados dos pacientes a distância. E com a preocupação em mente, Kangas [44], de que a população idosa está crescendo rapidamente, e as lesões relacionadas com as quedas é uma questão fundamental para esta população, que quer viver em casa de forma independente e segura, e por que não, utilizando de novas tecnologias, como detectores de queda automatizados, propôs comparar algoritmos para detecção de queda dos idosos. O pesquisador, avaliou diferentes algoritmos de baixa complexidade de detecção de queda, utilizando acelerômetros triaxial, anexados à cintura, punho e cabeça. Os dados foram obtidos a partir de um padrão de quedas intencionais (frente, para trás e laterais), para três indivíduos de meia idade, e utilizando-se de três diferentes algoritmos. Foram investigadas as fases de um evento da queda com: início da queda; a velocidade; o impacto; e a postura após a queda. Os resultados indicaram que o detector é eficiente, mesmo com algoritmos simples, com uma sensibilidade de 97 a $98 \%$. [44]

E no local da aplicação de Usabilidade, reunindo Cirurgia/Cuidados Intensivos receberam 7\% (6 de 75). Localizados como Emergências/Pronto Socorros, 6\% (5 de 75). Para Telemedicina, 5\% (4 de 75). No Laboratório Eletrônica/Automação cerca de 4\% (3 de 75), e para os Ambulatórios e Laboratórios de Análises Clínicas, igualmente 1\% (1 de $75)$. 


\section{CONCLUSÃO}

Nesta Revisão Sistemática da Literatura ressaltamos o quanto o Brasil está longe do ideal, elaborando escassas publicações e pouca aplicação da Engenharia da Usabilidade no desenvolvimento dos Dispositivos Médicos, apesar de ser compulsória, por falta de investimentos em equipes multidisciplinares de Engenharia da Usabilidade, na formação de pessoal especializado nas universidades, e reduzido treinamento dos usuários nos EAS pelos fabricantes.

Nos estudos analisados, respondendo à Questão 1, foram encontrados maior investimento na aplicação da Engenharia da Usabilidade, no Hardware dos Dispositivos Médicos, do que nos Softwares ou Processos, pois o foco principal destas avaliações é o próprio equipamento, mais do que os softwares/processos que já são testados pelos fabricantes.

Entretando, para a Questão 2, os resultados estão na contramão dos especialistas, que estão aplicando a Engenharia da Usabilidade, após o Dispositivo Médico estar pronto (Avaliação do Produto), do que seria desejável, fazê-lo ainda no processo de design (Desenvolvimento do Produto), a fim de descobrir perigos relacionados com o uso, se existir algum, ainda no ciclo de desenvolvimento do produto, e nunca o iniciar somente quando o DM está a caminho do mercado.

A revisão demostrou que se destacaram as técnicas da Análise de Tarefas e a Simulação de Cenários, respondendo à Questão 3, como as que mais estão sendo aplicadas para avaliação da Usabilidade nos Dispositivos Médicos. Onde observa-se, que os benefícios dos testes de usabilidade de dispositivos médicos vão muito além atender às exigências normativas e aumentar a facilidade de uso de um dispositivo. Os investimentos em testes de usabilidade podem beneficiar fabricantes, com a otimização do tempo e custo de desenvolvimento, aumentando as vendas, simplificando o treinamento e o suporte ao produto, e reduzindo as possíveis ações judiciais, e se pagam por si só, segundo estudos [4].

Outro aspecto identificado, para a Questão 4, é que o público alvo dessas pesquisas se destaca o Usuário/Paciente, como ser mais importante e mais enfatizado nos periódicos científicos. 
Das especialidades médicas que mais investiram na Engenharia da Usabilidade, respondendo à Questão 5, foi a Gastroenterologia, especialidade que na maioria das pesquisas, aplicaram Testes de Usabilidade descrevendo redesign ou protótipos de equipamentos para diagnóstico, que conduzem a detecção de câncer, exames de colonoscopia, endoscopia, ou instrumentos como o laparoscópico, demonstrando a inquietação com equipamentos extremamente delicados e de grande risco a saúde humana. Seguida da especialidade de Imagens/Medicina Nuclear, em função da revolução que o processamento de imagens digitais tem causado no meio médico, das imagens produzidas, a possibilidade de adquirir dados, armazenando e resgatando imagens de forma remota, disponibilizando toda a informação de diagnóstico, demonstra que o design do DM seja centrado no usuário.

E para o local onde se aplicou a Engenharia da Usabilidade com mais ênfase, foram os Dispositivos Médicos em atendimento ao Homecare, que com os avanços no domínio de dispositivos portáteis, surgem inúmeras ferramentas para o campo da Telemedicina Móvel, com aplicações médicas que podem servir como ferramenta de diagnóstico, que podem obter grande riqueza de dados dos pacientes a distância.

Em relação a Metodologia utilizada, se tivesse de refazer o trabalho, reduziria a quantidade de itens muito pulverizados que pouco se destacaram nas pesquisas, para que as tabelas de resultados fossem mais reduzidas. 


\section{TRABALHOS FUTUROS}

Diante dos resultados obtidos nesta Revisão Sistemática de Literatura, é fato que temos: normas reguladores/normalizadores; porém prática precária de Engenharia de Usabilidade no desenvolvimento dos Dispositivos Médicos; e que parte dos eventos adversos possui relação direta com erros de utilização de equipamentos médicos; e que poderiam ser prevenidos ou minimizados com a participação do usuário no projeto (user-centered design); e que faltam pesquisas sobre Usabilidade no Brasil; e como proposta provocar uma aproximação entre os órgãos normalizadores/reguladores de sáude: Ministério da Saúde, ABNT, Anvisa; reunidos com os instrumentos de formação/educação: Universidades (UnB) e Institutos Federais (IFB), com o objetivo de estimular uma aproximação entre eles, focando suas ações em conjunto, para elaborar ações de mudanças desta realidade, iniciando com as seguintes sugestões: 1) Capacitar e educação continuada, dos médicos, enfermeiros, cuidadores, administradores e outros profissionais de saúde, para entendimento das ferramentas de Usabilidade; 2) Promover projetos de melhorias da segurança do paciente, aplicando os princípios em conjunto com os estudantes de medicina e de cursos técnicos; 3) Elaborar programs de pós-graduação para produzir um maior número de profissionais qualificados; e 4) Expandir investimentos na formação dos cursos técnicos, para que todos possam aplicar as exigências mínimas das normas, para produzirem produtos com a operação mais eficientes, seguros, eficazes e confiáveis. 


\section{REFERÊNCIAS BIBLIOGRÁFICAS}

[1] ALOULOU, H. et al. 25)Deployment of assistive living technology in a nursing home environment: methods and lessons learned.(Research article)(Report). BMC Medical Informatics and Decision Making. vol. 13. pp. 42. 2013.

[2] MENDES, W. M., M.; Rozenfeld, S.; Travassos, C. The assessment of adverse events in hospitals in Brazil. International Journal for Quality in Health Care. vol. 21. no. 4. pp. p. 279-284. 2009.

[3] BRONZINO, J. D. e. a. Biotechnology for biomedical engineers. p.^pp. 232p. Boca Raton, FL: CRC Press. 2005.

[4] WIKLUND, M. E. K., Jonathan; Strochlic, Allison Y. . Usability testing of medical devices. Boca Ration, FL: CRC Press. 2011.

[5] MONEY, A. G. et al. The role of the user within the medical device design and development process: medical device manufacturers' perspectives. BMC Med Inform Decis Mak. vol. 11. pp. 15. 2011.

[6] FRIES, R. C. Reliable Design of Medical Devices. New York: CRC Press. 2006.

[7] RUBIN, J., CHISNELL, D. Handbook of Usability Testing: How to Plan, Design, and Conduct Effetive Test. 2a ed. Indianapolis, IN: Wiley Publishing, Inc. 2008.

[8] DAVIS, P. L.-Y., R.; Schug, S.; et al. (Nova Zelandia) Adverse events regional feasibility study: indicative findings. N Z Med J. vol. 114. pp. 203-5. 2001.

[9] WILSON, R. M. R., W. B.; Gibbert, R. W.; et al. (Australiano) The quality in Australiano health care study. Br Med J. vol. 163. pp. 458-71. 1995.

[10] VINCENT, C. N., G.; Woloshynowych, M. (Inglaterra) Adverse events in British hospitals: preliminary retrospective record review. Br Med J. vol. 322. pp. 517-9. 2001.

[11] SCHIOLER, T. L., H.; Pedersen, B.L.; et al. . (Dinamarques) Adverse Event Study, incidence of adverse events in hospitals. A retrospective study of medical records. . Ugeskr Laeger. vol. 164. pp. 4377-9. 2002.

[12] MICHEL, P. Q., J. L.; Sarasqueta, A. M.; et al. (Francês) Comparison of three methods for estimating rates of adverse events and rates of preventable adverse events in acute care hospitals. Br Med J. vol. 328. pp. 199-202. 2004. 
[13] ARANAZ-ANDRÉS, J. M. A.-R., C.; Vitaller-Murillo, J.; et al. (Espanhol) Incidence of adverse events related to health care in Spain: results of the Spanish National Study of Adverse Events. J Epidemiol Community Health. vol. 62. pp. 1022-9. 2008.

[14] Author. Documento de referência para o Programa Nacional de Segurança do Paciente. Department. Brasilia-DF. p. 40p, 2014.

[15] VINCENT, C. J. L., Y.; Blandford, A. Integration of human factors and ergonomics during medical device design and development: It's all about communication. Applied Ergonomics. vol. 45. pp. 413-419. 2014.

[16] MONEY, A. G. et al. The role of the user within the medical device design and development process: medical device manufacturers' perspectives.(Research article)(Report). BMC Medical Informatics and Decision Making. vol. 11. pp. 15. 2011.

[17] LEHOUX, P. M., F. A.; Hivon, M.; Demers-Payette, O.; Urbach, D. R. Clinicians as health technology designers: Two contrasting tales about user involvement in innovation development. Health Policy and Technology. vol. 2. pp. 122-130. 2013.

[18] ANVISA. Manual de Processo Administrativo Sanitário em Alimentos - Livro 1 e 2.Brasília. p., Date, 2008.

[19] EDUARDO, M. B. d. P. M., I. C. S. Saúde \& Cidadania - Vigilância Sanitária. São Paulo: Instituto para o Desenvolvimento da Saúde - IDS. Núcleo de Assistência Médico-Hospitalar. NAMH/FSP. Banco Itaú. 1998.

[20] BRASIL. Constituição da República Federativa do Brasil.FEDERAL, S.Brasília, DF. p. 292p, Date, 1988.

[21] Author. Estoque Regulatório da Anvisa - Macrotema Produtos para Saúde. Department. Brasília-DF. p., 2016.

[22] SHAH, S. G., and ROBINSON, I. Benefits of and barriers to involving users in medical device technology development and evaluation. Int J Technol Assess Health Care. vol. 23. no. 1. pp. 131-7. Winter. 2007.

[23] ABNT. ABNT NBR IEC 62366: Produtos para a saúde - Aplicação da engenharia de usabilidade a produtos para a sáude.Rio de Janeiro. p. 109p, Date, 2016.

[24] GURSES, A. P. O., A. A.; PRONOVOST, P. J. Time to accelerate integration of human factors and ergonomics in patient safety. BMJ Qual Saf. vol. 21. pp. 347-351. 2011. 
[25] CLAMANN, M. K., D. B. Applicability of Usability Evaluation Techniques to Aviation Systems. The International Journal of Aviation Psychology: Lawrence Erlbaum Associates. vol. 14(4). pp. 395-420. 2004.

[26] SALVEMINI, A. V. Challenges for user-interface designers of telemedicine systems. Telemed Jornal. vol. 5(2). pp. 163-168. 1999.

[27] BASS, L. J., B. E. Supporting usability through software architecture. Computer: Pittsburgh. vol. 34. no. 10. pp. 113-115. 2001.

[28] SAURO, J. "Timeline of Usability Infographic," 10/Nov, 2014; http://www.measuringu.com/blog/usability-infographic.php.

[29] FDA. "FDA Adverse Event Reporting System (FAERS) Statistics," 10/Nov/2014; http://www.fda.gov/Drugs/GuidanceComplianceRegulatoryInformation/Surveillanc e/AdverseDrugEffects/ucm070093.htm.

[30] BRASIL. Relatório do Quantitativo de notificações/Número de notificações por mês de eventos adversos.SANITÁRIA, N.-S. d. N. e. V.Brasília-DF. p., Date, 2013.

[31] WHO. Global priority areas for Patient Safety research. WORLD HEALTH ORGANIZATION. 2016.

[32] ALVES, C. S. Gestão de Tecnologias em Saúde: Desafios para o Engenheiro Biomédico. Engenharia Biomédica. FGA/UnB Gama. Brasília/DF. 2015.

[33] FABBRI, A. C. P. F. e. a. Externalising tacit knowledge of the systematic review process. Empirical Studies in Software Engineering. pp. 10p. 23.Ago.2013. 2013.

[34] SAMPAIO, R. F. M., M. C. Estudos de Revisão Sistemática: Um Guia para Síntese Criteriosa da Evidência Científica. Revista Brasileira de Fisioterapia. vol. v.11. no. n.1. pp. p. 83-89. 2007. 2007.

[35] ISA, C. T. S. et al. 32)Modeling of the medical device development process. 2012.

[36] MYKITYSHYN, A. L. F. A. D. R., W. A. Learning to use a home medical device: mediating age-related differences with training. SAGE Journals. vol. 44. pp. 354364. 2002.

[37] ZHANG, J. e. a. Using usability heuristics to evaluate patient safety of medical devices. Journal of Biomedical Informatics - Patient safety. vol. 36. no. 1/2. pp. 2330. February 20032003. 
[38] FREEMAN, T. 'Best practice' in focus group research: making sense of different views. Methodological Issues in Nursing Research. vol. 56(5). pp. 491-497. 7.July.2006. 2006.

[39] TRIOLA, M. A. Introdução à Estatística. 7a Ed. ed. Rio de Janeiro - RJ: LTC Editora. 1999.

[40] BURNFIELD, J. M. et al. 3)Impact of elliptical trainer ergonomic modifications on perceptions of safety, comfort, workout, and usability for people with physical disabilities and chronic conditions. Physical therapy. vol. 91. no. 11. pp. 1604. 2011.

[41] FURNISS, D. et al. 4)7 Themes for guiding situated ergonomic assessments of medical devices: A case study of an inpatient glucometer. Applied Ergonomics. vol. 45. no. 6. pp. 1668-1677. 2014.

[42] HAAK, T. et al. 7)Comparison of usability and patient preference for the new disposable insulin device solostar versus flexpen, lilly disposable pen, and a prototype pen: an open-label study.(Author abstract). Clinical Therapeutics. vol. 29. no. 4. pp. 650. 2007.

[43] ROBINSON, J. et al. 14)Skin Self-Examination Education for Early Detection of Melanoma: A Randomized Controlled Trial of Internet, Workbook, and In-Person Interventions. Journal Of Medical Internet Research. vol. 16. no. 1. 2014.

[44] GÖRGES, M., and STAGGERS, N. 19)Evaluations of Physiological Monitoring Displays: A Systematic Review. Journal of Clinical Monitoring and Computing. vol. 22. no. 1. pp. 45-66. 2008.

[45] EVERARD, M. L. 22)The Emperor's New Clothes II-time for regulators to wake up and take responsibility for unnecessary asthma morbidity: time for the second aerosol 'transition'. Thorax. vol. 68. no. 9. pp. 891. 2013.

[46] MATSUMOTO, K. et al. 23)Development and clinical usability of a new traction device " medical ring" for endoscopic submucosal dissection of early gastric cancer. Surgical endoscopy. vol. 27. no. 9. pp. 3444. 2013.

[47] SWEET, R. M. 26)Review of trainers for transurethral resection of the prostate skills. Journal of endourology / Endourological Society. vol. 21. no. 3. pp. 280. 2007.

[48] DE BOER, E. et al. 27)A Standardized Light-Emitting Diode Device for Photoimmunotherapy. The Journal of Nuclear Medicine. vol. 55. no. 11. pp. 1893. 2014. 
[49] WROBLEWSKI, D. et al. 31)Testing of Visual Field with Virtual Reality Goggles in Manual and Visual Grasp Modes. BioMed Research International. 2014.

[50] FENG, T.-H., and LIU, H.-E. 36)Initial evaluation of a new safety needle system at a clinical setting in Taiwan.(Report). International Journal of Nursing Practice. vol. 15. no. 5. pp. 394. 2009.

[51] KIM, S. et al. 42)Effects of two hospital bed design features on physical demands and usability during brake engagement and patient transportation: A repeated measures experimental study. International Journal of Nursing Studies. vol. 46. no. 3. pp. 317-325. 2009.

[52] LANG, A. R. et al. 46)The effect of design on the usability and real world effectiveness of medical devices: A case study with adolescent users. Applied Ergonomics. vol. 44. no. 5. pp. 799-810. 2013.

[53] ANTINORI-LENT, K. J. 49)Analysis of comparison of patient preference for two insulin injection pen devices in relation to patient dexterity skills. Journal of diabetes science and technology. vol. 6. no. 4. pp. 917. 2012.

[54] ZHU, Z., and JI, Q. 57)Novel eye gaze tracking techniques under natural head movement. IEEE transactions on bio-medical engineering. vol. 54. no. 12. pp. 2246. 2007.

[55] ZHU, Z. J., Q. 58)Novel eye gaze tracking techniques under natural head movement. IEEE transactions on bio-medical engineering vol. Vol.54(12), . pp. 2246-60p. 2007.

[56] PARK, E. Y. et al. 60)Tracheal intubation using the Airtraq.sup.[R]: a comparison with the lightwand. (Report). Anaesthesia. vol. 65. no. 7. pp. 729. 2010.

[57] LANGLEY, A., and MAR FAN, G. 62)Comparison of the glidescope?, flexible fibreoptic intubating bronchoscope, iPhone modified bronchoscope, and the Macintosh laryngoscope in normal and difficult airways: a manikin study.(Research article)(Author abstract). BMC Anesthesiology. vol. 14. pp. 10. 2014.

[58] STEFFEN, A. et al. 63)User-friendly design of a drug delivery system for Parkinson patients. Biomedical Engineering-Biomedizinische Technik. vol. 57. 2012.

[59] KATO, M. et al. 64)Prospective, randomized comparison of 3 different hemoclips for the treatment of acute upper GI hemorrhage in an established experimental setting. Gastrointestinal endoscopy. vol. 75. no. 1. pp. 3. 2012. 
[60] TUIJTHOF, G. J. M. et al. 67)A novel foot plate to assess 3D range of motion of the hindfoot.(Report). International Journal of Industrial Ergonomics. vol. 42. no. 1. pp. 41. 2012.

[61] KAPPELGAARD, A., and HANSEN, N. 68)Comparison of injection dose force, accuracy and precision among three growth hormone injection devices. Expert Review Of Medical Devices. vol. 10. no. 3. pp. 321-327. 2013.

[62] HUGENECK, R. 73)From art to part: a collaborative approach: expanding the collaboration between device makers and contract manufacturers can help shorten a new device's time to market whilst optimising cost, quality and compliance.(MARKETPLACE: OUTSOURCING OUTLOOK). European Medical Device Technology. vol. 1. no. 8. pp. 36. 2010.

[63] WALJI, M. F. et al. 74)Detection and characterization of usability problems in structured data entry interfaces in dentistry. International Journal of Medical Informatics. vol. 82. no. 2. pp. 128-138. 2012.

[64] WHITING, M. et al. 79)Designing for the End-User: Human Factors Engineering. Medical Design Technology. pp. n/a. 2015.

[65] ANONYMOUS. 80)Perspectives on patient safety. Medical Design Technology. vol. 19. no. 2. pp. 8. 2015.

[66] BRUSCO, S. 81)Come on in MedTech, make yourself at home.(Applying Tech: Human Factors in Home Healthcare)(Interview). vol. 19. no. 6. pp. 11. 2015.

[67] RAPAPORT, R. et al. 82)Validation and ease of use of a new pen device for selfadministration of recombinant human growth hormone: results from a two-center usability study. Medical Devices : Evidence and Research. vol. 2013. no. default. pp. 141-146. 2013.

[68] KUSELMAN, I., and PENNECCHI, F. 84)Human errors and measurement uncertainty. Human errors and measurement uncertainty. vol. 52. no. 2. pp. 238-243. 2015.

[69] SMITH, R. et al. 90)Comparative analysis of the functionality of simulators of the da Vinci surgical robot. Surg Endosc. vol. 29. no. 4. pp. 972-983. 2015.

[70] HÖSS, A. et al. 91)First experiences with the implementation of the European standard EN 62304 on medical device software for the quality assurance of a radiotherapy unit. Radiation Oncology (London, England). vol. 9. pp. 79-79. 2014. 
[71] MONEY, A. B., J.; Kuljis, J.; Money, A. 107)Public Claims about Automatic External Defibrillators: An Online Consumer Opinions Study. BMC Public Health. vol. Vol.11. pp. 332-332p. 2011.

[72] BERNAL DEL NOZAL, J. 108)Polyp Localization and Segmentation in Colonoscopy Images by Means of a Model of Appearance for Polyps. ELCVIA. Electronic letters on computer vision and image analysis. vol. 13. no. 2. pp. 9-10. 2014.

[73] GOUDAR, V., and POTKONJAK, M. 110)Fault-Tolerant and Low-Power Sampling Schedules for Localized BASNs. Emerging and Selected Topics in Circuits and Systems, IEEE Journal on. vol. 3. no. 1. pp. 86-95. 2013.

[74] CHAO, C. et al. 114)Comparative Efficacy of New Interfaces for Intra-procedural Imaging Review: the Microsoft Kinect, Hillcrest Labs Loop Pointer, and the Apple iPad. Journal of Digital Imaging. vol. 27. no. 4. pp. 463-9. 2014.

[75] RODRIGUEZ, C. et al. 115)Development of a communication intervention to assist hospitalized suddenly speechless patients. Technology and Health Care. vol. 20. no. 6. pp. 489-500. 2012.

[76] NAKAI, A. et al. 116)Investigating the effects of motion-based Kinect game system on user cognition. J Multimodal User Interfaces. vol. 9. no. 4. pp. 403-411. 2015.

[77] AMINI, N. et al. 125)Accelerometer-based on-body sensor localization for health and medical monitoring applications. Pervasive and Mobile Computing. vol. 7. no. 6. pp. 746-760. 2011.

[78] FAIRBANKS, R. J. et al. 126)Usability Study of Two Common Defibrillators Reveals Hazards. Annals of Emergency Medicine. vol. 50. no. 4. pp. 424-432. 2007.

[79] MARTIN, J. L. et al. 127)A user-centred approach to requirements elicitation in medical device development: A case study from an industry perspective. Applied Ergonomics. vol. 43. no. 1. pp. 184-190. 2012.

[80] SCHMETTOW, M. et al. 128)With how many users should you test a medical infusion pump? Sampling strategies for usability tests on high-risk systems. Journal of Biomedical Informatics. vol. 46. no. 4. pp. 626-641. 2013.

[81] GRANT, T. 131)The involvement of users in the design of home use medical devices: challenges and incentives for change. United Kingdom. 2014. 
[82] BARRINGTON, S. 132)Usability in the Lab: Techniques for Creating Usable Products. Journal of the Association for Laboratory Automation. vol. 12. no. 1. pp. 6-11. 2007.

[83] RAPAPORT, R. et al. 134)Validation and ease of use of a new pen device for selfadministration of recombinant human growth hormone: results from a two-center usability study. Medical devices (Auckland, N.Z.). vol. 6. pp. 141. 2013.

[84] FUNG, C. H. et al. 138)Human factors/ usability barriers to home medical devices among individuals with disabling conditions: In-depth interviews with positive airway pressure device users. Disability and Health Journal. vol. 8. no. 1. pp. 86-92. 2015.

[85] GURALNICK, M. L. et al. 139)InTone: a novel pelvic floor rehabilitation device for urinary incontinence.(Report). vol. 26. no. 1. pp. 99. 2015.

[86] BERGMAN, E. 143)Introduction to human factors. Journal of diabetes science and technology. vol. 6. no. 2. pp. 229. 2012.

[87] BJØRN ERIK, M. et al. 146)Constructing, enacting and packaging innovations. European Journal of Innovation Management. vol. 9. no. 4. pp. 444-465. 2006.

[88] SCHWARZENBACH, F. et al. 147)Results of a human factors experiment of the usability and patient acceptance of a new autoinjector in patients with rheumatoid arthritis. Patient Preference and Adherence. vol. 2014. no. default. pp. 199-209. 2014.

[89] LANGE, J. et al. 148)Usability of devices for self-injection: results of a formative study on a new disposable pen injector. Medical Devices : Evidence and Research. vol. 2014. no. default. pp. 195-203. 2014.

[90] KAISER, I. et al. 149)Usability of therapy controllers in elderly patients with deep brain stimulation. BMC Neurology. vol. 12. no. 1. pp. 4. 2012.

[91] LILJEGREN, E. 152)Usability in a medical technology context assessment of methods for usability evaluation of medical equipment. International Journal of Industrial Ergonomics. vol. 36. no. 4. pp. 345-352. 2006.

[92] MAHNKE, A. P., J.; Hoffman, D.; Partridge, N.; Foth, W.; Waudby, C.; Rasmussen, L.; McManus, V.; McCarty, C. 153)A rural community's involvement in the design and usability testing of a computer-based informed consent process for the personalized medicine research project. American Journal of Medical Genetics Part A. vol. 164. no. 1. pp. 129-140. 2014. 
[93] MONEY, A. G. et al. 159)The role of the user within the medical device design and development process: medical device manufacturers' perspectives. BMC Medical Informatics and Decision Making. vol. 11. pp. 15-15. 2011.

[94] AMREIN, K. et al. 162)Glucose control in intensive care: usability, efficacy and safety of Space GlucoseControl in two medical European intensive care units. BMC endocrine disorders. vol. 14. pp. 62. 2014.

[95] CARDENAS, G., and DE LA ROSA, A. 163)Usability of virtual reality environments to treat posttraumatic stress disorder for criminal violence victims.(POSTER PRESENTATIONS)(Report). Journal of CyberTherapy and Rehabilitation. vol. 4. no. 2. pp. 284. 2011.

[96] TORRES-VILLALOBOS, G. et al. 165)Evaluation of the usability of virtual scenarios as auxiliaries for obesity treatment.(POSTER PRESENTATIONS)(Clinical report). Journal of CyberTherapy and Rehabilitation. vol. 4. no. 2. pp. 296. 2011.

[97] JOLLY, J. D. et al. 166)Better Instructions for Use to Improve Reusable Medical Equipment (RME) Sterility. Human Factors: The Journal of Human Factors and Ergonomics Society. vol. 55. no. 2. pp. 397-410. 2013.

[98] WANG, R. M., A.; Dutta, T.; Fernie, G. W.; Rosalie. 175)Usability testing of multimodal feedback interface and simulated collision-avoidance power wheelchair for long-term-care home residents with cognitive impairments. Journal of Rehabilitation Research and Development. vol. Vol.48(7). pp. 801p. 2011.

[99] GILBERTSON, M. W., and ANTHONY, B. W. 176)Force and Position Control System for Freehand Ultrasound. Robotics, IEEE Transactions on. vol. 31. no. 4. pp. 835-849. 2015.

[100] GEIDL, L. et al. 177)Usability and Safety of Ventricular Assist Devices: Human Factors and Design Aspects.(Report). Artificial Organs. vol. 33. no. 9. pp. 691. 2009.

[101] SCHIEFER, C. et al. 181)A technical support tool for joint range of motion determination in functional diagnostics - an inter-rater study.(Research). Journal of Occupational Medicine and Toxicology (London). vol. 10. pp. 16. 2015.

[102] ADAMS, R. et al. 182)Do older patients find multi-compartment medication devices easy to use and which are the easiest? Age and Ageing. vol. 42. no. 6. pp. 715-720. 2013.

[103] LEITRITZ, M. A. et al. 183)Usability of a gravity- and tilt-compensated sensor with data logging function to measure posturing compliance in patients after macular hole 
surgery: a pilot study.(Report)(Author abstract). Graefe's Archive for Clinical and Experimental Ophthalmology. vol. 252. no. 5. pp. 739. 2014.

[104] MCCRORY, B. et al. 184)Comparative usability testing of conventional and single incision laparoscopic surgery devices. Human factors. vol. 55. no. 3. pp. 619. 2013.

[105] DE FALCO, I. et al. 186)An integrated system for wireless capsule endoscopy in a liquid-distended stomach. IEEE transactions on bio-medical engineering. vol. 61. no. 3. pp. 794. 2014.

[106] COOK, T. M. et al. 189)A simulation-based evaluation of two proposed alternatives to Luer devices for use in neuraxial anaesthesia.(Report). Anaesthesia. vol. 65. no. 11. pp. 1069. 2010.

[107] ALSHAER, H. et al. 190)A system for portable sleep apnea diagnosis using an embedded data capturing module. Journal of Clinical Monitoring and Computing. vol. 27. no. 3. pp. 303-11. 2013.

[108] HARMS, F. et al. 191)Cutaneous mitochondrial respirometry: non-invasive monitoring of mitochondrial function. Journal of Clinical Monitoring and Computing. vol. 29. no. 4. pp. 509-519. 2015.

[109] WU, Y.-H. et al. 194)Acceptance of an assistive robot in older adults: a mixedmethod study of human--robot interaction over a 1-month period in the Living Lab setting.(ORIGINAL RESEARCH)(Report). vol. 9. pp. 801. 2014.

[110] BELLINI, P. et al. 9)Mobile emergency, an emergency support system for hospitals in mobile devices: pilot study. JMIR research protocols. vol. 2. no. 1. pp. e19. 2013.

[111] NIV, Y., and TAL, Y. 18)Developing a tool to preserve eye contact with patients undergoing colonoscopy for pain monitoring. Drug, Healthcare and Patient Safety. vol. 2012. no. default. pp. 103-105. 2012.

[112] WEE, J. N. S. 20)Providing personal health records in Malaysia: a portable prototype. School Of Engineering, Computing And Science. Swinburne University Of Technology. Australia. 2012.

[113] WOLKOWSKI, B. et al. 24)Assessment of freeware programs for the reconstruction of tomography datasets obtained with a monochromatic synchrotron-based X-ray source. Journal of Synchrotron Radiation. vol. 22. no. 4. pp. 1130. 2015.

[114] ZAFAR, A. 43)A prototype user interface for a mobile electronic clinical note entry system. AMIA - Annual Symposium proceedings. AMIA Symposium. pp. 1165p. 2005. 
[115] KANGAS, M. et al. 44)Comparison of low-complexity fall detection algorithms for body attached accelerometers.(Report). Gait \& Posture. vol. 28. no. 2. pp. 285. 2008.

[116] NEMODA, Z. et al. 53)Assessing genetic polymorphisms using DNA extracted from cells present in saliva samples. BMC medical research methodology. vol. 11. pp. 170. 2011.

[117] SHAH, N. J. et al. 54)Anatomy of an Anesthesia Information Management System. Anesthesiology Clinics. vol. 29. no. 3. pp. 355-365. 2011.

[118] SHINTARO, O. C., Jose ; Sanz, Silvia ; Henseler, Jorg Shintaro, Okazaki. 56)Factors Affecting Mobile Diabetes Monitoring Adoption Among Physicians: Questionnaire Study and Path Model. Journal of Medical Internet Research. vol. Vol.14(6). 2012.

[119] GUERLAIN, S. et al. 71)Intelliject's novel epinephrine autoinjector: sharps injury prevention validation and comparable analysis with EpiPen and Twinject. Annals of Allergy, Asthma \& Immunology. vol. 105. no. 6. pp. 480-484. 2010.

[120] PECK, R. et al. 85)What Should the Ideal HIV Self-Test Look Like? A Usability Study of Test Prototypes in Unsupervised HIV Self-Testing in Kenya, Malawi, and South Africa. AIDS Behav. vol. 18. no. 4. pp. 422-432. 2014.

[121] YOO, S. et al. 88)Development and User Research of a Smart Bedside Station System toward Patient-Centered Healthcare System. J Med Syst. vol. 39. no. 9. pp. 1-11. 2015.

[122] MITCHELL, K. B. et al. 94)Effects of brief training on use of automated external defibrillators by people without medical expertise. Human factors. vol. 50. no. 2. pp. 301. 2008.

[123] GEISSLER, N. et al. 99)Patient safety related to the use of medical devices: A review and investigation of the current status in the medical device industry. Biomedizinische Technik. vol. 58. no. 1. pp. 67-78. 2013.

[124] SHAH, S. et al. 109)Developing medical device technologies from users' perspectives: A theoretical framework for involving users in the development process. International Journal Of Technology Assessment In Health Care. vol. 25. no. 4. pp. 514-521. 2009.

[125] RUITER, J. G. et al. 111)Robotic control of a traditional flexible endoscope for therapy. Journal of Robotic Surgery. vol. 7. no. 3. pp. 227. 2013. 
[126] MALHOTRA, S. L., Archana ; Keselman, Alla ; Zhang, Jiajie ; Patel, Vimla L. 119)Designing the design phase of critical care devices: a cognitive approach. Journal of Biomedical Informatics. vol. Vol.38(1). pp. 34-50p. 2005.

[127] PARK, H. S. et al. 123)Development of Cell Phone Application for Blood Glucose Self-Monitoring Based on ISO/IEEE 11073 and HL7 CCD. Healthcare informatics research. vol. 21. no. 2. pp. 83. 2015.

[128] ELKIN, P. L. 130)Human Factors Engineering in HI: So What? Who Cares? and What's in It for You? Healthcare informatics research. vol. 18. no. 4. pp. 237. 2012.

[129] CHOI, M. et al. 137)Usability of Academic Electronic Medical Record Application for Nursing Students' Clinical Practicum. Healthcare informatics research. vol. 21. no. 3. pp. 191. 2015.

[130] KÜBLER, A. et al. 170)The User-Centered Design as Novel Perspective for Evaluating the Usability of BCI-Controlled Applications. PLoS One. vol. 9. no. 12. pp. e112392. 2014.

[131] SHAH, S. G. S., and ROBINSON, I. 10)Benefits of and barriers to involving users in medical device technology development and evaluation. International Journal of Technology Assessment in Health Care. vol. 23. no. 1. pp. 131-137. 2007.

[132] FLEWWELLING, C. J. et al. 12)The use of fault reporting of medical equipment to identify latent design flaws. Journal of Biomedical Informatics. vol. 51. pp. 80-85. 2014.

[133] LANGE, J. et al. 16)Usability of a new disposable autoinjector platform device: results of a formative study conducted with a broad user population. Medical Devices : Evidence and Research. vol. 2015. no. default. pp. 255-264. 2015.

[134] MACKERT, M. et al. 34)Patient Education on Mobile Devices: An E-Health Intervention for Low Health Literate Audiences. Journal of Information Science. vol. 35. no. 1. pp. 82-93. 2009.

[135] VAN DER PEIJL, J. et al. 47)Design for risk control: The role of usability engineering in the management of use-related risks. Journal of Biomedical Informatics. vol. 45. no. 4. pp. 795-812. 2012.

[136] GAUSEPOHL, K. et al. 48)Using Storytelling to Elicit Design Guidance for Medical Devices. Ergonomics in Design: The Quarterly of Human Factors Applications. vol. 19. no. 2. pp. 19-24. 2011. 
[137] BOTSCH, H. et al. 75)The packaging connection: creating better pharmaceutical and medical products with packaging partnerships.(Packaging partnerships). Pharmaceutical Technology Europe. vol. 21. no. 1. pp. 28. 2009.

[138] VITRANI, M. A. et al. 83)PROSBOT - Model and image controlled prostatic robot. IRBM. 2015.

[139] WILCOX, S. B., and DRUCKER, D. 178)Implications of the new Food and Drug Administration draft guidance on human factors engineering for diabetes device manufacturers. Journal of diabetes science and technology. vol. 6. no. 2. pp. 231. 2012.

[140] BLIGARD, L., and OSVALDER, A. L. 185)CCPE: Methodology for a Combined Evaluation of Cognitive and Physical Ergonomics in the Interaction between Human and Machine. Human Factors And Ergonomics In Manufacturing \& Service Industries. vol. 24. no. 6. pp. 685-711. 2014.

[141] JAN, A., and RADERMACHER, K. 8)Usability first; Model-based approach for the use-oriented risk analysis of medical devices/Usability First; Modellbasierter Ansatz zur nutzungsorientierten Risikoanalyse von Medizinprodukten.(Report). Bundesgesundheitsblatt - Gesundheitsforschung - Gesundheitsschutz. vol. 57. no. 12. pp. 1384. 2014.

[142] SUPPA, M. et al. 29)Testmed. Process management in Emergency Medicine. Prevention and Research : International Open Access Journal of Prevention and Research in Medicine. vol. 3. no. 1. pp. 16-25. 2013.

[143] BUSSE, H. et al. 86)Targeting Accuracy, Procedure Times and User Experience of 240 Experimental MRI Biopsies Guided by a Clinical Add-On Navigation System. PLoS ONE. vol. 10. no. 7. 2015.

[144] VINCENT, C. J., and BLANDFORD, A. 11)Usability standards meet scenario-based design: Challenges and opportunities. Journal of Biomedical Informatics. vol. 53. pp. 243-250. 2015.

[145] MATSUMOTO, K. et al. 30)Development and clinical usability of a new traction device " medical ring" for endoscopic submucosal dissection of early gastric cancer. Surg Endosc. vol. 27. no. 9. pp. 3444-3451. 2013.

[146] DONAWA, M. E. 98)European medical device usability requirements: manufacturers marketing medical devices in Europe need to be able to demonstrate compliance with the newly clarified usability requirements introduced by directive 2007/47/EC. This article discusses European usability requirements, relevant 
European standards and important ethical considerations.(REGULATIONS AND STANDARDS). European Medical Device Technology. vol. 2. no. 6. pp. 12. 2011.

[147] ELIAS, B. L. et al. 112)Evaluation of nursing student perspectives of a simulated smart pump. Clinical Simulation in Nursing. vol. 9. no. 12. pp. 599-606. 2013.

[148] MANCUSO, P. J. et al. 122)Can Patient Use of Daily Activity Monitors Change Nurse Practitioner Practice? The Journal for Nurse Practitioners. vol. 10. no. 10. pp. 787-793.e4. 2014.

[149] CAREY, M. L., D.; Murray, K.; Stevenson, J. C., Mark 169)Reliability, validity, and clinical usability of a digital goniometer. vol. Vol.36(1). pp. 55-66p. 2010.

[150] VOOIJS, M. A., L. L.; Snoeck-Stroband, J. B.; Beerthuizen, T.; Siemonsma, P. C.; Abbink, J. J.; Sont, J. K.; Rövekamp, T. A. 174)Validity and usability of low-cost accelerometers for internet-based self-monitoring of physical activity in patients with chronic obstructive pulmonary disease. Interactive journal of medical research. vol. 3. no. 4. pp. e14. 2014.

[151] LEMKE, M. R., and WINTERS, J. M. 179)Removing barriers to medical devices for users with impairments. Ergonomics in Design. vol. 16. no. 3. pp. 18-25. 2008.

[152] LINDL, B. L., and MUELLER, R. G. 193)TOPOS: A new topometric patient positioning and tracking system for radiation therapy based on structured white light. Medical Physics. vol. 40. no. 4. 2013.

[153] ITURRATE, I. et al. 195)Exploiting Task Constraints for Self-Calibrated BrainMachine Interface Control Using Error-Related Potentials. PLoS One. vol. 10. no. 7. 2015.

[154] ANONYMOUS. 5)Blood product positive patient identification: comparative simulation-based usability test of two commercial products.(Clinical report). Transfusion. vol. 51. no. 11. pp. 2311. 2011.

[155] CHO, Y. B. et al. 6)Natural orifice transluminal endoscopic surgery applied to sigmoidectomy in survival animal models: using paired magnetic intra-luminal device.(Report). Surgical Endoscopy. vol. 25. no. 4. pp. 1319. 2011.

[156] SCHWARZENBACH, F. et al. 13)Results of a human factors experiment of the usability and patient acceptance of a new autoinjector in patients with rheumatoid arthritis. Patient Preference And Adherence. vol. 8. pp. 199-209. 2014. 
[157] RICCI, Z. S., G.; Bonello, M.; Ratanarat, R.; Andrikos, E.; Dan, M.; Piccinni, P.; Ronco, C. 37)A new machine for continuous renal replacement therapy: from development to clinical testing. Expert review of medical devices vol. Vol.2(1)

pp. 47-55p. 2005.

[158] GONZALEZ-VARGAS, J. et al. 38)Human-Machine Interface for the Control of Multi-Function Systems Based on Electrocutaneous Menu: Application to MultiGrasp Prosthetic Hands. PLoS One. vol. 10. no. 6. 2015.

[159] AMREIN, K. et al. 173)Glucose control in intensive care: usability, efficacy and safety of Space GlucoseControl in two medical European intensive care units.(Research article)(Report). BMC Endocrine Disorders. vol. 14. pp. 62. 2014.

[160] MCALEARNEY, A. S. S., S. B.; Medow, M. A. 45)Organizational and physician perspectives about facilitating handheld computer use in clinical practice: results of a cross-site qualitative study. Journal of the American Medical Informatics Association - JAMIA. vol. Vol.12(5). pp. 568-75p. 2005.

[161] MENTLER, T. et al. 133)Routine Mobile Applications for Emergency Medical Services in Mass Casualty Incidents. Biomedical Engineering-Biomedizinische Technik. vol. 57. 2012.

[162] GEIDL, L. et al. 17)Intuitive Use and Usability of Ventricular Assist Device Peripheral Components in Simulated Emergency Conditions.(Report). Artificial Organs. vol. 35. no. 8. pp. 773. 2011.

[163] LOTTRIDGE, D. et al. 95)Requirements analysis for customization using subgroup differences and large sample user testing: A case study of information retrieval on handheld devices in healthcare. International Journal Of Industrial Ergonomics. vol. 41. no. 3. pp. 208-218. 2011.

[164] CORDEIRO, L. F., B.; Chen, H.; Silva, J. M. Semiformal Verification of Embedded Software in Medical Devices Considering Stringent Hardware Constraints. pp. 8p. 22.Abr.2016. 2009.

[165] IEC. IEC 62304:2006 - Medical Device Software - Software Life Cycle Processes.Geneva, Switzerland. p. 151, Date, 2006.

[166] ABNT. ABNT NBR ISO 14971:2009: Produtos para a saúde - Aplicação de gerenciamento de risco a produtos para a saúde.Rio de Janeiro. p. 88p, Date, 2009.

[167] FRIES, J. F. S., P.; KRAINES, R. G.; HOLMAN, H. R. Measurement of patient outcome in arthritis. Arthritis \& Rheumatism. vol. 23. pp. 137-145. 2005. 
[168] BLIGARD, L. O., AL. CCPE: Methodology for a Combined Evaluation of Cognitive and Physical Ergonomics in the Interaction between Human and Machine. Web of Science. vol. 24. no. 6. pp. 685-711. 2014.

[169] MARTIN, J. L. M., E.; CROWE, J. A.; NORRIS, B. J. Capturing User Requirements in Medical Device Development: The Role of Ergonomics. Institute os Physics Publishing. Physiological Measurement. vol. 27. pp. 49 - 62. 13 Jun.2006. 2006.

[170] SAURO, J. L., J. R. Quantifying The User Experience. Waltham, Massachusetts, USA: Elsevier Inc. 2012.

[171] WEBSTER, J. e. a. Medical Instrumentation: Application And Design. 4th Ed. ed. John Wiley \& Sons, INC. 2010. 